\title{
Redox Switches in Noise-Induced Cardiovascular and Neuronal Dysregulation
}

\begin{abstract}
Katie Frenis ${ }^{1,2}$, Marin Kuntic ${ }^{1}$, Omar Hahad ${ }^{1,3}$, Maria Teresa Bayo Jimenez ${ }^{1}$, Matthias Oelze ${ }^{1}$, Steffen Daub ${ }^{1}$, Sebastian Steven ${ }^{1}$, Thomas Münzel ${ }^{1,3 \dagger *}$ and Andreas Daiber ${ }^{1,3 \dagger *}$

${ }^{1}$ Department of Cardiology, Molecular Cardiology, University Medical Center, Mainz, Germany, ${ }^{2}$ Boston Children's Hospital and Harvard Medical School, Boston, MA, United States, ${ }^{3}$ German Center for Cardiovascular Research (DZHK), Partner Site RhineMain, Mainz, Germany
\end{abstract}

OPEN ACCESS

Edited by:

Giuseppe Valacchi,

North Carolina State University,

United States

Reviewed by: Claudia Penna

University of Turin, Italy Judit Marsillach,

University of Washington, United States

*Correspondence: Andreas Daiber

daiber@uni-mainz.de

Thomas Münzel

tmuenzel@uni-mainz.de

${ }^{\dagger}$ These authors have contributed equally to this work and share senior authorship

Specialty section: This article was submitted to

Cellular Biochemistry,

a section of the journal

Frontiers in Molecular Biosciences

Received: 28 September 2021

Accepted: 28 October 2021

Published: 18 November 2021

Citation:

Frenis $K$, Kuntic $M$, Hahad $O$, Bayo Jimenez MT, Oelze M, Daub S, Steven S, Münzel $T$ and Daiber $A$ (2021) Redox Switches in NoiseInduced Cardiovascular and Neuronal Dysregulation.

Front. Mol. Biosci. 8:784910. doi: $10.3389 /$ fmolb.2021.784910
Environmental exposures represent a significant health hazard, which cumulatively may be responsible for up to 2/3 of all chronic non-communicable disease and associated mortality (Global Burden of Disease Study and The Lancet Commission on Pollution and Health), which has given rise to a new concept of the exposome: the sum of environmental factors in every individual's experience. Noise is part of the exposome and is increasingly being investigated as a health risk factor impacting neurological, cardiometabolic, endocrine, and immune health. Beyond the well-characterized effects of high-intensity noise on cochlear damage, noise is relatively well-studied in the cardiovascular field, where evidence is emerging from both human and translational experiments that noise from traffic-related sources could represent a risk factor for hypertension, ischemic heart disease, diabetes, and atherosclerosis. In the present review, we comprehensively discuss the current state of knowledge in the field of noise research. We give a brief survey of the literature documenting experiments in noise exposure in both humans and animals with a focus on cardiovascular disease. We also discuss the mechanisms that have been uncovered in recent years that describe how exposure to noise affects physiological homeostasis, leading to aberrant redox signaling resulting in metabolic and immune consequences, both of which have considerable impact on cardiovascular health. Additionally, we discuss the molecular pathways of redox involvement in the stress responses to noise and how they manifest in disruptions of the circadian rhythm, inflammatory signaling, gut microbiome composition, epigenetic landscape and vessel function.

Keywords: sources of reactive oxygen species, redox switches, oxidative stress, cardiovascular disease, neuronal complications, traffic noise exposure

Abbreviations: A $\beta$, amyloid beta; ACTH, adrenocorticotropic hormone; BMAL1, brain and muscle arnt-like protein; BH4 tetrahydrobiopterin; CLOCK, circadian locomotor output cycles kaput; CRP, C-reactive protein; CRY, cryptochrome; d, day; $\mathrm{dB}$, decibel; DHE, dihydroethidium; eNOS, endothelial NOS; FOXO, forkhead box O; FBXL3, F-Box and leucine rich repeat protein 3; h, hour; HPA, hypothalamic-pituitary-adrenal; HO-1, heme oxygenase-1; IL, interleukin; LysM, lysozyme M; NFkB, nuclear factor kappa-light-chain-enhancer of activated B cells; nNOS, neuronal NOS; NOS, nitric oxide synthase; Nox2, NADPH oxidase 2; Nrf2, nuclear factor-erythroid factor 2; PKC, protein kinase C, PYK-2, protein tyrosine kinase 2; ROS, reactive oxygen species; SNS, sympathetic nervous system; SPL, sound pressure level; TNFa, tumor necrosis factor alpha; WHO, world health organization. 


\section{INTRODUCTION}

Around $50 \%$ of the world's population currently resides in urban environments, following a trend of increasing worldwide urbanization which is expected to continue in the near future (The World Bank, 2020). By 2050, the United Nations (UN) estimates that 6.68 billion people will reside in cities (United Nations, 2018). These demographic shifts, alongside the SARSCoV-2 pandemic pushing the employment paradigm towards a scheme of working from home (Pew Research Center, 2020), make a healthy home environment and healthy urban planning more important than ever (Munzel et al., 2021b). As an important component of the exposome (Wild, 2005), or the cumulation of health-related exposures over the course of life (Vrijheid, 2014; Sainani, 2016; Vineis et al., 2020), excess noise is an increasingly recognized health risk factor to which urban dwellers are particularly susceptible because it is found at potentially hazardous levels in highly trafficked areas and in areas surrounding airports. The effects of noise have been wellquantified in the context of occupational hearing loss, wherein it has been reported that 22 million Americans are exposed to hazardous levels of noise per year (Tak et al., 2009), and several studies have indicated that exposure to levels of noise above 85 decibels $(\mathrm{dB})$ in industrial settings has a correlation with increased systolic blood pressure (Kerns et al., 2018; Li et al., 2019b). These numerous studies do not account for exposures at low or moderate levels outside of the workplace, which are sound pressure levels more relevant to daily exposures. Noise from more common sources has also recently been implicated as harmful as put forward in the most recent World Health Organization (WHO) Noise Guidelines for the European Region (2018) and meta-analysis thereof (Guski et al., 2017; Clark and Paunovic, 2018; Kempen et al., 2018). Based on the latter data, significant health effects have already become evident upon chronic exposure to an average sound pressure level of $>45 \mathrm{~dB}(\mathrm{~A})$ during the night and $>55 \mathrm{~dB}(\mathrm{~A})$ during the day. Traffic noise, particularly during the night, appears to be a major contributor to the noise burden of the average person (Sorensen et al., 2011; Heritier et al., 2019; Munzel et al., 2020).

Traffic noise arises from several sources and can span a wide variety of intensities and frequencies, making the correlation between exposure and effects on human health difficult to fully elucidate. The Caerphilly study was established in 1984 and was conducted until the mid-1990s with the goal of correlating ischemic heart disease with road traffic noise exposure using exposure levels as mapped in 1984. The study did not find a significant association between ischemic heart disease and noise exposure (51-70 dBA, 6-22 h), but did uncover associations between risk factors including increased systolic blood pressure, estradiol, total cholesterol, plasma viscosity, antithrombin III, cortisol, and decreased platelet count (Babisch et al., 1988). These data provided the first notable insights into risk posed to cardiovascular health by noise below the threshold commonly accepted as being hazardous. Since these initial insights, many more population-based studies have been conducted (reviewed in detail in Münzel et al. Munzel et al., 2018a; Munzel et al., 2020; Munzel et al., 2021a). Amongst

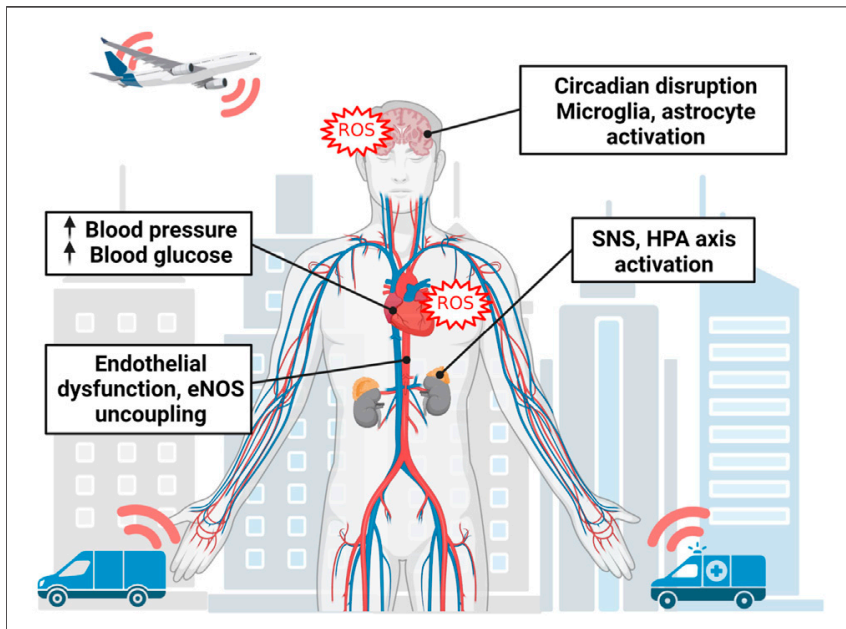

FIGURE 1 | Overall mechanism of noise-triggered adverse health effects. Noise perception starts in the brain leading to neuronal activation in association with disruption of circadian rhythms (especially by nighttime noise causing sleep deprivation and fragmentation), neuroinflammation and cerebral oxidative stress. Noise activates down-stream stress responses such as activation of the sympathetic nervous system (SNS) and the hypothalamicpituitary-adrenal (HPA) axis leading to stress hormone release such as catecholamines and cortisol with secondary activation of the reninangiotensin-aldosterone system. This cascade will converge in oxidative stress and inflammation in association with eNOS uncoupling, endothelial dysfunction and high blood pressure as well as hyperglycemia, well-known triggers of cardiovascular sequela. Image was created using Biorender.com.

these were 22 studies yielding high quality evidence linking road traffic noise and incidence, prevalence, or mortality from ischemic heart disease (van Kempen et al., 2002; Kempen et al., 2018). Correlations between traffic noise exposure and other cardiovascular diseases like hypertension, stroke, and diabetes were generally positive but suffered from low quality evidence due to heterogeneity of methods (van Kempen et al., 2002; European Region, 2018). These epidemiological findings are particularly concerning given the near-ubiquitous presence of noise; the WHO has estimated that $40 \%$ of Europeans are exposed to road traffic noise exceeding the strongly recommended daytime level of $55 \mathrm{~dB}(\mathrm{~A})$ and $30 \%$ exceed the lower level of $45 \mathrm{~dB}(\mathrm{~A})$ recommended at night (Fritschi et al., 2011). More densely populated Asian urban centers could exceed even those estimates, with a noise day-evening-night level $\left(\mathrm{L}_{\mathrm{den}}\right)$ of 60-65 dB(A) (Lelieveld et al., 2015).

The epidemiological evidence that associates traffic noise with onset and progression of cardiovascular disease is abundant, but in order to truly understand how noise and cardiovascular disease are connected, deeper mechanistic insights are necessary. In human field studies, vitamin $\mathrm{C}$ was shown to alleviate endothelial dysfunction associated with one night of aircraft noise exposure (Schmidt et al., 2013; Herzog et al., 2019). This implies that oxidative stress has an important role in the underlying pathophysiology (Heitzer et al., 2001), which is also compatible with a number of cardiovascular sequela that were associated with noise exposure (Figure 1). It was even shown that aircraft noise exposure for one night increased the 
serum levels of 3-nitrotyrosine-positive proteins in patients with established coronary artery disease (Schmidt et al., 2015; KrollerSchon et al., 2018), whereas train noise exposure for one night caused a shift to pro-oxidative and pro-atherothrombotic milieu of the plasma proteome in healthy volunteers (Herzog et al., 2019). These studies (Schmidt et al., 2013; Herzog et al., 2019) and others (Schmidt et al., 2021) have demonstrated that the interruption of sleep may be an important mechanism for prompting this pro-oxidative environment, and in exposure while awake, annoyance in response to noise appears to be correlated to anxiety and depression (Beutel et al., 2016; Beutel et al., 2020) as well as atrial fibrillation (Hahad et al., 2018; Hahad et al., 2021b). These human lines of evidence for a role of oxidative stress or adverse redox signaling for noise-induced adverse (cardiovascular) health effects were further supported by numerous mechanistic animal studies that will be discussed in detail within this review and were already partially summarized previously (Munzel et al., 2018a; Munzel et al., 2018b; Munzel et al., 2020; Munzel et al., 2021a).

\section{ANIMAL RESEARCH ON NOISE-INDUCED CARDIOVASCULAR AND NEURONAL DYSREGULATION}

Research into the mechanisms by which noise exerts detrimental impact on human health has been underway for decades, though it has been intermittent. An important paradigm was put forth by Babisch (Babisch, 2002), which stipulates that noise could have both a direct and indirect pathway in its impact on human health. The direct pathway entails auditory damage by high-intensity sound exposure, which culminates in damage of the inner ear and stress responses (Figure 1). The indirect pathway is relevant to "sub-hazardous" noise exposures, including traffic noise, and manifests as annoyance or disturbance of sleep. These cognitive/emotional and physiological responses intersect with the direct pathway by causing stress responses, which can then manifest as cardiometabolic disease (Daiber et al., 2019a). There is overlap between the adverse effects of stress and sleep disruption, which are cardiovascular risk factors in their own right, but can also lead to increases in catecholamine, adrenocorticotropic hormone (ACTH), and cortisol secretion, circadian disruption and decreased melatonin production, decreased insulin sensitivity and leptin levels, increases in ghrelin and appetite, upregulation of inflammatory proteins such as tumor necrosis factor alpha (TNFa), interleukins (e.g., IL1, IL6), and C-reactive protein (CRP), as well as increases in oxidative stress (Medic et al., 2017). Importantly, stress responses are triggered in the brain and activate the sympathetic nervous system (SNS), hypothalamic-pituitary-adrenal (HPA) axis, and endocrine systems which can lead to presentation of the aforementioned cardiovascular risk factors through hormonal signaling (Daiber et al., 2019a).

The noise reaction scheme has been generally upheld by preclinical work in the field of noise research (Munzel et al., 2018a; Munzel et al., 2018b; Munzel et al., 2020; Munzel et al., 2021a). Evidence that stress responses are a key component in the appearance and exacerbation of cardiovascular risk factors has been both explicitly and tangentially explored. Enhanced glutaminergic signaling in the amygdala of rats (Singewald et al., 2000) and amygdalar activation in humans (Osborne et al., 2020; Hahad et al., 2021a; Osborne et al., 2021) demonstrates a stress-induced arousal in response to noise. Activation of the HPA axis is evident in the increased plasma corticosterone of noise-exposed rats and increases in plasma cortisol in noise-exposed mice aligns with readouts of sympathetic activation, adrenaline and noradrenaline, increased in plasma and kidney of noise-exposed mice (Munzel et al., 2017) and rats (Gannouni et al., 2013). Activation of these stress response systems accounts for the adverse cardiovascular readouts detected in noise-exposed animals, which includes several reports of increases in blood pressure (Peterson et al., 1981; Peterson et al., 1984a), increased myocardial fibrosis (Herrmann et al., 1994), as well as atrial interstitial fibrosis (Lousinha et al., 2020). Our own work sheds light on the molecular workings behind these effects. Using our standardized noise exposure protocol, we reliably report elevation of blood pressure in noise-exposed animals, which exacerbates preexisting hypertension. Our model also finds increases in leukocyte infiltration into the aortic endothelium, causing endothelial dysfunction (Kroller-Schon et al., 2018) that appears to be phagocytic NADPH oxidase (Nox2) (Kroller-Schon et al., 2018) and macrophage/monocyte-dependent (Frenis et al., 2021). These effects can be prevented by induction of the antioxidant principle nuclear factor E2 related factor-2 (Nrf2)/heme oxygenase 1 (HO-1) axis (Bayo Jimenez et al., 2021), implying a critical link between oxidative stress and the onset of adverse cardiovascular effects of noise. This postulate is also supported by numerous oxidative stress markers found in noise-exposed animals such as 3-nitrotyrosine-, malondialdehyde- or 4-hydroxynonenal-positive proteins in different tissues and plasma/serum as well as S-glutathionylated endothelial nitric oxide synthase (eNOS) and uncoupled neuronal nitric oxide synthase (nNOS) and directly measured reactive oxygen species (ROS) formation by high performance liquid chromatography (HPLC)-based quantification of 2-hydroxyethidium and various other staining techniques or oxidative burst (Munzel et al., 2017; Kroller-Schon et al., 2018; Kvandova et al., 2020; Steven et al., 2020; Frenis et al., 2021). Classical biomarkers of oxidative stress such as malondialdehyde-, 4-hydroxynonenal or 3-nitrotyrosine-positive proteins (described for various cardiovascular disease conditions Daiber and Chlopicki, 2020; Daiber et al., 2021) were also observed upon noise exposure.

For a full accounting of the studies of noise exposure in animals with a focus on non-auditory damage see Table 1 . However, it is noteworthy that studies arising from different laboratories use different protocols for noise exposure, which accounts for variation in the time of day and duration of the exposure, the length of the noise event (if nonconstant), the type of noise, and the species of the subject.

\section{REDOX SWITCHES ACTIVATED BY NOISE EXPOSURE}

Oxidative stress is a central pathomechanism in response to noise exposure as demonstrated by genetic deletion of the 
TABLE 1 | Studies on non-auditory noise effects on cardiovascular and endothelial dysfunction, inflammation or oxidative stress in animals ${ }^{a}$. Only articles that are not discussed in detail in the main article text are listed here.

\begin{tabular}{|c|c|c|c|c|}
\hline Study & $\begin{array}{l}\text { Animals and } \\
\text { model }\end{array}$ & Noise scenario & Major outcome of noise exposure & Ref \\
\hline Peterson 1981 & $\begin{array}{l}\text { Rhesus } \\
\text { Monkey }\end{array}$ & $\begin{array}{l}85 \mathrm{~dB}, 97 \mathrm{~dB} \text { peak, unknown } \\
\text { type, } 9 \text { months }\end{array}$ & Blood pressure elevation $\sim 30 \mathrm{mmHg}$ & Peterson et al. (1981) \\
\hline Borg 1981 & Rat & $\begin{array}{l}80 \mathrm{~dB}, 100 \mathrm{~dB} \text {, unknown type, } \\
10 \mathrm{~h} \text {, lifelong }\end{array}$ & $\begin{array}{l}\text { Noise-exposed spontaneously hypertensive rats had } \\
\text { shorter lifespan and higher incidence of cardiovascular } \\
\text { disease, but no differences were found in normotensive } \\
\text { rats }\end{array}$ & Borg and Jarplid (1981) \\
\hline Peterson 1984 & $\begin{array}{l}\text { Macaque } \\
\text { Monkey }\end{array}$ & $\begin{array}{l}86.6 \mathrm{~dB} \text {, construction noise, } 4 \mathrm{~h} / \\
8 \mathrm{~h}, 97 \text { days }\end{array}$ & $\begin{array}{l}\text { Mean blood pressure elevation remained elevated after } \\
\text { noise cessation, but heart rate returned to normal } \\
\text { relatively quickly }\end{array}$ & Peterson et al. (1984b) \\
\hline Kirby 1984 & $\begin{array}{l}\text { Macaque } \\
\text { Monkey }\end{array}$ & $95 \mathrm{~dB}$, broadband noise, $30 \mathrm{~m}$ & $\begin{array}{l}\text { Offspring of hypertensive monkeys were more sensitive } \\
\text { to blood pressure increases from loud noise }\end{array}$ & Kirby et al. (1984) \\
\hline Dengerink 1985 & Guinea Pigs & 120 dB, white noise, $30 \mathrm{~m}$ & $\begin{array}{l}\text { Effects in cochlear vessel lumen and RBC behavior } \\
\text { appear to normalize after } 2 \text { days of "noise washout" }\end{array}$ & Dengerink et al. (1985) \\
\hline Paparelli 1992 & Rat & $100 \mathrm{~dB}$, white noise, $12 \mathrm{~h}$ & $\begin{array}{l}\text { Increased density of noradrenergic cardiac fibers in } \\
\text { young animals. In aged animals, increased aortic } \\
\text { maximal response to the } \alpha \text {-agonist on the aortic } \\
\text { musculature and reduced responsiveness to the } \\
\beta \text {-agonist in cardiac fibers }\end{array}$ & Paparelli et al. (1992) \\
\hline Morvai 1994 & Rat & $\begin{array}{l}95 \mathrm{dBA} \text {, industrial noise, } 6 \mathrm{~h} \text {, } \\
3 \text { weeks }\end{array}$ & $\begin{array}{l}\text { Noise and alcohol modify the } a \text {-adrenergic effect of } \\
\text { noradrenaline }\end{array}$ & Morvai et al. (1994) \\
\hline Herrmann 1994 & Rat & $\begin{array}{l}65 \text { dBA, unknown type, } \\
52 \text { weeks }\end{array}$ & $\begin{array}{l}\text { Increased microvessel area, cardiac fibrosis, and } \\
\text { ischemic myocardial lesions in SHR exposed to noise }\end{array}$ & Herrmann et al. (1994) \\
\hline Breschi 1995 & Rat & $100 \mathrm{~dB}$, white noise, $1 \mathrm{~h} / 6 \mathrm{~h}$ & $\begin{array}{l}\text { Diazepam and clonazepam pre-treatment reversed the } \\
\text { effects of noise on CBR binding and protected cardiac } \\
\text { tissue and aortic responses from the effects of } 6 \mathrm{~h} \text { noise } \\
\text { stress }\end{array}$ & Breschi et al. (1995) \\
\hline Salvetti 2000 & Rat & $100 \mathrm{dBA}$, white noise, 6/12 h & $\begin{array}{l}\text { Significant decrease in the binding sites availability of } \\
\text { peripheral benzodiazepine receptors following noise }\end{array}$ & Salvetti et al. (2000) \\
\hline Singewald 2000 & Rat & $95 \mathrm{~dB}$, unknown type, 3 m & $\begin{array}{l}\text { Noise stress resulted in exaggerated glutaminergic } \\
\text { responses in the amygdala of SHR versus Wistar-Kyoto }\end{array}$ & Singewald et al. (2000) \\
\hline Bauer 2001 & Sheep & $\begin{array}{l}161 \mathrm{~dB} \text {, airborne impulse noise, } \\
20 \text { impulses }\end{array}$ & $\begin{array}{l}\text { Fetal heart rate was affected in both REM and NREM } \\
\text { sleep, power of delta, theta, and alpha band power was } \\
\text { reduced and cortical activity was detected }\end{array}$ & Bauer et al. (2001) \\
\hline Gesi 2002 & Mouse & 100 dBA, white noise, $6 \mathrm{~h}$ & $\begin{array}{l}\text { Cardiomyocytes from the right atria and left ventricles } \\
\text { display disarranged cristae and matrix dilution in } \\
\text { mitochondria }\end{array}$ & Gesi et al. (2002) \\
\hline Lenzi 2003 & Rat & $100 \mathrm{dBA}$, white noise, $12 \mathrm{~h}$ & $\begin{array}{l}\text { Increased catecholamine content in myocardium, DNA } \\
\text { damage in cardiomyocytes, mitochondrial membrane } \\
\text { swelling in right atrium }\end{array}$ & Lenzi et al. (2003) \\
\hline Frenzilli 2004 & Rat & 100 dBA, white noise, $12 \mathrm{~h}$ & $\begin{array}{l}\text { DNA damage in the adrenal gland, possible redox } \\
\text { involvement }\end{array}$ & Frenzilli et al. (2004) \\
\hline Baldwin 2007 & Rat & $\begin{array}{l}90 \mathrm{~dB}, \text { unknown type, } 15 \text { m, 3/ } \\
5 \text { weeks }\end{array}$ & $\begin{array}{l}\text { Noise increased leakiness of mesenteric arteries, } \\
\text { mitigated by vitamin c }\end{array}$ & Baldwin and Bell (2007) \\
\hline Antunes 2013 & Rat & $\begin{array}{l}90 \mathrm{~dB} \text {, low frequency, unknown } \\
\text { duration }\end{array}$ & $\begin{array}{l}\text { Significant myocardial fibrosis detected via CAB staining } \\
\text { and alterations in connexin } 43 \text { and collagen expression in } \\
\text { noise-exposed rats }\end{array}$ & $\begin{array}{l}\text { Antunes et al. (2013a); Antunes et al. } \\
\text { (2013b); Antunes et al. (2013c) }\end{array}$ \\
\hline $\begin{array}{l}\text { Arpornchayanon } \\
2013\end{array}$ & Guinea Pigs & 106 dB, unknown type, 30 m & $\begin{array}{l}\text { TNF-a signaling is activated in the cochlea following } \\
\text { noise exposure, causing vessel constriction. Improved } \\
\text { by etanercept. }\end{array}$ & Arpornchayanon et al. (2013) \\
\hline Gannouni 2013 & Rat & $\begin{array}{l}70 \mathrm{~dB}, 80 \mathrm{~dB}, \text { unknown type, } \\
6 \mathrm{~h}, 90 \text { days }\end{array}$ & $\begin{array}{l}\text { Increased corticosterone levels, affected various } \\
\text { parameters of the endocrine glands and cardiac } \\
\text { function. Markers of oxidative stress (catalase, } \\
\text { superoxide dismutase and lipid peroxidation) were } \\
\text { increased }\end{array}$ & Gannouni et al. (2013) \\
\hline Gannouni 2014 & Rat & $\begin{array}{l}70 \mathrm{dBA} \text {, unknown type, } 6 \mathrm{~h} / \text { day, } \\
3 / 5 \mathrm{~m}\end{array}$ & $\begin{array}{l}\text { Structural alterations within the adrenal gland consistent } \\
\text { with chronic stress. Signs of necrosis and inflammation } \\
\text { in myocardium }\end{array}$ & Gannouni et al. (2014) \\
\hline Said 2016 & Rat & $\begin{array}{l}80-100 \mathrm{~dB} \text {, chronic and } \\
\text { intermittent, unknown type, } 8 \mathrm{~h} \text {, } \\
20 \text { days }\end{array}$ & $\begin{array}{l}\text { Increases in plasma levels of corticosterone, adrenaline, } \\
\text { noradrenaline, endothelin-1, nitric oxide and } \\
\text { malondialdehyde. Decreases in superoxide dismutase }\end{array}$ & Said and El-Gohary (2016) \\
\hline
\end{tabular}

(Continued on following page) 
TABLE 1 | (Continued) Studies on non-auditory noise effects on cardiovascular and endothelial dysfunction, inflammation or oxidative stress in animals ${ }^{\text {a }}$. Only articles that are not discussed in detail in the main article text are listed here.

\begin{tabular}{|c|c|c|c|c|}
\hline Study & $\begin{array}{l}\text { Animals and } \\
\text { model }\end{array}$ & Noise scenario & Major outcome of noise exposure & Ref \\
\hline Lyamin 2016 & Beluga Whale & $\begin{array}{l}140-175 \mathrm{~dB} \text {, unknown type, } \\
2-4 \text { h, } 60 \text { events }\end{array}$ & $\begin{array}{l}\text { Heart rate acceleration following noise exposure. Calves } \\
\text { were more susceptible to the effects of noise and did not } \\
\text { habituate }\end{array}$ & Lyamin et al. (2016) \\
\hline Konkle 2017 & Rat & $\begin{array}{l}87.3 \text { dBA, unknown type, } \\
15 \text { min-1 h, } 21 \text { days }\end{array}$ & $\begin{array}{l}\text { Plasma ACTH, adrenal gland weight, IL6, IL1b levels } \\
\text { were unchanged following noise exposure. Increases in } \\
\text { TNF } \alpha \text { and CRP were seen. }\end{array}$ & Konkle et al. (2017) \\
\hline Lousinha 2018 & Rat & $\begin{array}{l}120 \mathrm{~dB} \text {, high intensity infrasound, } \\
28 \text { days }\end{array}$ & $\begin{array}{l}\text { Exposed mice had prominent perivascular tissue with } \\
\text { notable fibrosis that was mitigated by dexamethasone } \\
\text { treatment. }\end{array}$ & Lousinha et al. (2018) \\
\hline Yang 2020 & Mouse & $\begin{array}{l}105 \text { dB SPL, unknown type, } \\
1 / 4 \text { h }\end{array}$ & $\begin{array}{l}\text { DNA damage response genes appear to fail to respond } \\
\text { to noise-induced DNA damage in cochlea, heart, liver, } \\
\text { and cortex }\end{array}$ & Yang and Guthrie (2020) \\
\hline Lousinha 2020 & Rat & $\begin{array}{l}120 \mathrm{~dB} \text {, high intensity infrasound, } \\
12 \text { weeks }\end{array}$ & $\begin{array}{l}\text { Atrial interstitial fibrosis was increased and connexin } 43 \\
\text { weas decreased following noise exposure }\end{array}$ & Lousinha et al. (2020) \\
\hline Kvandova 2020 & Mouse & $\begin{array}{l}72 \text { dBA, intermittent aircraft, } \\
4 \text { days }\end{array}$ & $\begin{array}{l}\text { Oxidative parameters and DNA damage increased } \\
\text { following noise exposure with synergetic increases in } \\
\mathrm{Ogg}^{-1-} \text { mice. }\end{array}$ & Kvandova et al. (2020) \\
\hline Gogokhia 2021 & Rat & $\begin{array}{l}\text { High intensity white noise, } 1 \mathrm{~h} \text {, } \\
10 \text { days }\end{array}$ & $\begin{array}{l}\text { Male rats show higher anxiety-like response following } \\
\text { noise }\end{array}$ & Gogokhia et al. (2021) \\
\hline $\begin{array}{l}\text { Bayo Jimenez } \\
2021\end{array}$ & Mouse & $\begin{array}{l}72 \text { dBA, intermittent aircraft, } \\
4 \text { days }\end{array}$ & $\begin{array}{l}\text { Induction of NRF2/HO-1 protected against oxidative } \\
\text { damage, normalized blood pressure, and vascular } \\
\text { endothelial function }\end{array}$ & Bayo Jimenez et al. (2021) \\
\hline
\end{tabular}

${ }^{a}$ Table was taken from $P h D$ thesis of Katie Frenis.

Nox2, which can completely prevent adverse noise effects (Kroller-Schon et al., 2018). We have also demonstrated additive effects of noise-induced oxidative stress with ROS formation originating from angiotensin-II triggered arterial hypertension, an animal model well-known for its pronounced activation of the Nox2 isoform of NADPH oxidases (Steven et al., 2020). Our laboratory also provided molecular proof that the phagocytic Nox2 in lysozyme M (LysM)-positive inflammatory cells (most probably monocytes and macrophages) is responsible for adverse cardiovascular effects of noise since genetic ablation of these LysM-positive cells (by diphtheria toxin treatment of mice with transgenic LysM-specific diphtheria toxin receptor expression) prevented noise-induced vascular oxidative stress, inflammation, endothelial dysfunction and increase in blood pressure (Frenis et al., 2021). A pro-oxidative phenotype was also revealed by RNA sequencing data indicating downregulation of genes encoding for antioxidant defense proteins such as superoxide dismutase 1 and glutathione peroxidase 1 as well as antioxidant transcription factors such as Forkhead box proteins O (FOXO) (Munzel et al., 2017). Untargeted plasma proteome analysis supported a pro-inflammatory phenotype in noise-exposed mice that was associated with a pro-oxidative shift in ratio of unsaturated to saturated fatty acids, enhanced interaction of leukocytes with the endothelium and overall microvascular dysfunction, which was all corrected by genetic deletion of Nox2 (Eckrich et al., 2021). The noise-induced oxidative stress leads to secondary damage such as adverse redox signaling on eNOS and nNOS as previously reviewed (Daiber et al., 2020). Direct scavenging of nitric oxide by the diffusion-controlled reaction with superoxide also represents a redox switch and supports an antagonistic action of superoxide on nitric oxide signaling (Daiber et al., 2017b).

\section{Noise Causes Activation of the Phagocytic NADPH Oxidase With Subsequent Redox Activation of Inflammatory Cells}

Professional phagocytes possess a powerful tool to aid in their innate immune activity: Nox2 (or gp91phox). Namely neutrophils, monocytes, macrophages, and their central nervous system (CNS) equivalent microglia are constitutive expressors of Nox2. While this enzyme is critically important in the normal defense against invading pathogens, it also has an apparent role in the development and progression of cardiovascular diseases, including endothelial dysfunction (Chan and Baumbach, 2013), hypertension (Murdoch et al., 2011), ischemic heart disease (Guzik et al., 2006), and atherosclerosis (Sorescu et al., 2002). Importantly, when reconstituting Nox2-containing wildtype monocytes back to LysM-positive cell ablated mice, the protection from angiotensin-II induced hypertension is absent-indicating that vascular impact of Nox2 expression is dominated by its abundance in phagocytic cells (Wenzel et al., 2011). Nox2 inhibition has also been shown to mitigate anxiety-like phenotypes and oxidative stress associated with chronic mild stress (Lv et al., 2019). Accordingly, our own studies demonstrate that upon noise exposure, Nox 2 protein and mRNA is consistently upregulated in the murine aorta (Munzel et al., 2017) alongside activation mechanisms of Nox2, such as angiotensin-II dependent diacylglycerol-mediated protein 


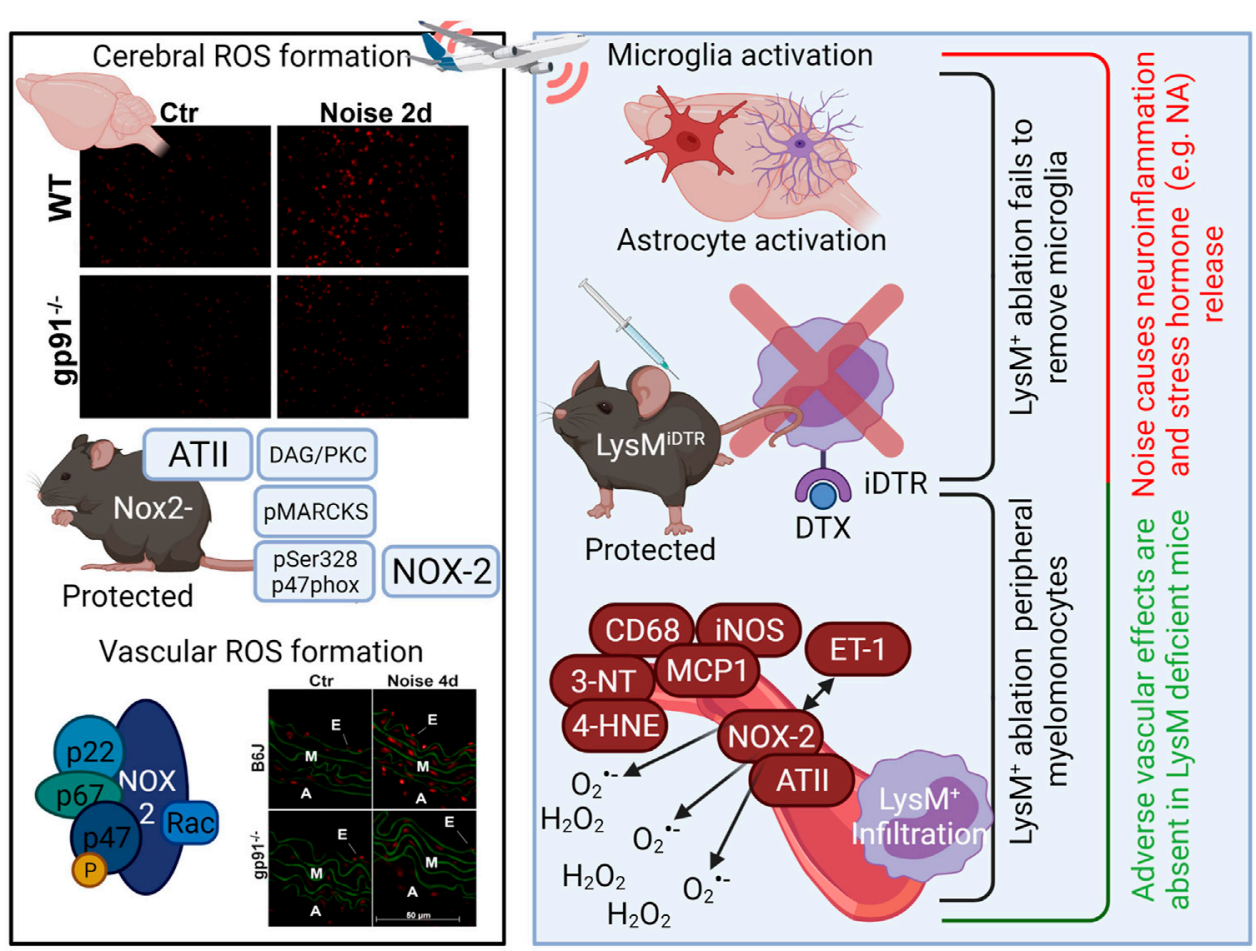

FIGURE 2|Activation of the phagocytic NADPH oxidase (Nox2, gp91phox) by noise (Kroller-Schon et al., 2018) and role of LysM-positive myelomonocytic cells for noise-induced cardiovascular inflammation and damage (Frenis et al., 2021). Noise causes cerebral and vascular ROS formation as envisaged by more pronounced dihydroethidium (DHE)-derived red fluorescence in cerebral and aortic cryo-sections that was partially corrected in gp91phox (Nox2) knockout mice (representative stainings). Nox2 activation by noise was probably based on angiotensin-II (ATII)-dependent AT1-receptor activation with subsequent activation of phospholipase $\mathrm{C}$ and diacylglycerol (DAG) formation, a strong protein kinase C (PKC) activator. PKC activation was documented by noise-triggered phosphorylation of the PKC target myristoylated, alanine-rich C kinase substrate (MARCKS) as well as phosphorylation of p47phox at serine 328, a regulatory cytosolic subunit of Nox2. Translocation of pSer328-p47phox, among other cytosolic regulators, to the cytoplasmatic membrane-bound gp91phox leads to full activation of Nox2 and subsequent superoxide formation. Genetic ablation by treatment of mice with LysM-positive cell (myelomonocytic) specific overexpression of an inducible diphtheria toxin receptor (LysM ${ }^{\text {iDTR }}$ ) with low dose diphtheria toxin (Wenzel et al., 2011). Mice free of LysM-positive cells showed no noise-dependent infiltration of monocytes, macrophages or granulocytes and preserved endothelial function, normal blood pressure and no aortic oxidative stress indicating that LysM-positive cell ablation protects the periphery from noiseinduced damage. In contrast, microglia in the brain of LysM ${ }^{\text {iDTR }}$ mice were not ablated by diphtheria toxin and noise-induced neuroinflammation, cerebral oxidative stress and release of stress hormones was not prevented. Image was created using Biorender.com. DHE staining images were reused from (Kroller-Schon et al., 2018) with permission.

kinase $\mathrm{C}$ activation with subsequent phosphorylation of the major cytosolic regulator of Nox2, p47phox, at serine 328 (Figure 2) (Kroller-Schon et al., 2018).

We also find that oxidative stress in the aorta, heart, and brains of noise-exposed mice is significantly increased over those of unexposed controls, which is entirely mitigated in mice with a genetic deletion of Nox2 (Kroller-Schon et al., 2018). These mice were similarly protected from increases in blood pressure, dysregulation of NO signaling, and endothelial dysfunction, which is in line with reports of NOX-derived superoxide being partially determinative in the endothelial dysfunction accompanying genetic, angiotensin, and deoxycorticosterone acetate (DOCA) salt hypertension (Laursen et al., 1997; Zalba et al., 2001; Harrison et al., 2003). Nox2 deletion also protected mice from microvascular dysfunction in the cerebral microvessels and proteomic analysis demonstrated that there was no noiseinduced increase in inflammatory signaling in the plasma (Eckrich et al., 2021). In addition, Nox2 inhibition by GSK2795039 suppressed ROS signals in cerebral cryo-sections of noise-exposed mice (Kroller-Schon et al., 2018). It may be also speculated that noise-induced ROS formation promotes an inflammatory phenotype in the heart, vessels and the brain as central mediators of inflammatory reactions such as the NLR family pyrin domain containing 3 (NLRP3) inflammasome and high-mobility group box 1 protein (HMGB1) are activated under oxidative stress conditions via redox switches as well as redoxsensitive transcription factors such as nuclear factor kappa B (NFkB) (Wenzel et al., 2017; Steven et al., 2019). This is probably the reason, aside from stress hormone-dependent activation and infiltration of immune cells into the vasculature, for the observed noise-triggered inflammation in exposed mice (Munzel et al., 2017; Kroller-Schon et al., 2018; Steven et al., 2020; Eckrich et al., 2021; Frenis et al., 2021) but also the shift to a proatherothrombotic phenotype of the plasma proteome of train noise-exposed healthy human subjects (Herzog et al., 2019), epigenetic changes that promote immune cell activation and expression of CRP (Cai et al., 2017; Eze et al., 2020) and amygdala activation driven coronary atherosclerosis (Osborne 
et al., 2020; Hahad et al., 2021a; Osborne et al., 2021). Noisemediated inflammation in mice was also prevented by genetic Nox2 deletion as shown by two independent preclinical studies (Kroller-Schon et al., 2018; Eckrich et al., 2021) and antioxidant pharmacological activation/induction of the Nrf2-HO1-axis (Bayo Jimenez et al., 2021).

We were able to further discern that Nox2-bearing cells were primarily responsible for noise-induced cardiovascular and cerebral damage through a selective ablation protocol targeting cells expressing lysozyme M. Monocytes and macrophages are generally $\mathrm{LysM}^{+}$, whereas microglia are only weakly LysM ${ }^{+}$or even LysM ${ }^{-}$. As a result, we found that upon ablation, blood pressure, endothelial function, and oxidative stress parameters were largely protected in the periphery (Figure 2) (Frenis et al., 2021). However, an exaggerated stress response measurable through plasma corticosterone level was seen in mice whose monocytes/macrophages were ablated, accompanied by a neuroinflammatory phenotype. Markers of microglial activation, CD68, CD86, and MHC-II, were significantly elevated in flow cytometry analysis of noiseexposed murine brains and not normalized by genetic ablation LysM-positive cells (Figure 2) (Frenis et al., 2021). This apparent disparity somewhat implies that the blood-brainbarrier may be affected by noise, which has been reported in hypertension as well (Setiadi et al., 2018). Furthermore, the prooxidative and pro-inflammatory environment appears to have also affected the state of astrocytes in the brains of noiseexposed mice, as an increase in $\mathrm{GFAP}^{+}$staining can be detected. These results are in line with reports of Nox2 activation in microglia in several pathologies affecting the cerebrovasculature (Simpson and Oliver, 2020) and may connect these studies in animals with data from the Gutenberg Health Study of 11,905 participants that demonstrates that annoyance to noise predicts depression and anxiety (Beutel et al., 2020).

\section{Noise Causes Inactivation and Uncoupling of eNOS}

The nitric oxide synthase (NOS) family is critically important for the normal functioning of vessels, due to their role in the production of bioavailable nitric oxide ( ${ }^{\bullet} \mathrm{NO}$ ) (Forstermann and Munzel, 2006; Daiber et al., 2019b). Because of the actions of ${ }^{\circ} \mathrm{NO}$, the presence of normally functioning eNOS and nNOS is cardioprotective (Schulz et al., 2008). However, there is a substantial chink in NOS's cardioprotective armor: eNOS requires a cofactor, tetrahydrobiopterin $(\mathrm{BH} 4)$, to facilitate the transfer of electrons in order to produce ${ }^{\circ} \mathrm{NO}$. The physiological consequence is that when $\mathrm{BH} 4$ levels are reduced, the rate at which this electron transfer occurs is slower than the rate of oxidative degradation, which effectively causes NOS to produce superoxide (Forstermann and Munzel, 2006). BH4 can be oxidized to an unusable form by ROS, which sets the stage for NOX-derived ROS to further "kindle" the production of other reactive intermediates by encouraging the uncoupling of NOS enzymes. In fact, superoxide is regarded as somewhat of a direct antagonist of nitric oxide (Gryglewski et al.,
1986; Daiber et al., 2017b). Decreased BH4 levels in response to noise exposure were so far not reported.

In addition to cofactor BH4 availability, eNOS is tightly regulated through redox mechanisms (Schulz et al., 2014; Daiber et al., 2017a). The redox status of eNOS greatly impacts its synthase activity and can be modulated by the presence of oxidative stress. There are several sites for phosphorylation which can either enhance or decrease the synthase activity of eNOS, however, the most common readouts of eNOS activity are at Ser1177 (Akt-dependent positive effect Dimmeler et al., 1999) as well as Tyr657 and Thr495 (both negative effects) (Figure 3). Importantly, all phosphorylations are redox-sensitive and stimuli-dependent, which is well-established for the protein tyrosine kinase 2 (PYK-2)-dependent phosphorylation at Tyr657 (Fisslthaler et al., 2008; Loot et al., 2009) and the protein kinase C (PKC)mediated phosphorylation at Thr495 (Fleming et al., 2001; Lin et al., 2003) as both kinases can be activated by hydrogen peroxide. In the presence of oxidative stress, eNOS can also undergo S-glutathionylation, leading to uncoupling (Chen et al., 2010; Karbach et al., 2014). Finally, peroxynitrite appears to have the ability to release zinc from the zincthiolate complex coordinating eNOS monomers in the active dimer, representing another mechanism for uncoupling via oxidative stress (Zou et al., 2002).

In our own noise studies, we consistently reported an overexpression and overactivation of NADPH oxidase (NOX) enzymes (Munzel et al., 2017; Kroller-Schon et al., 2018; Steven et al., 2020). It is most likely that due to this overexpression of superoxide-producing enzymes, eNOS in the aorta (and nNOS in the brain) uncouples following noise exposure, as shown by dihydrethidium staining with eNOS inhibitor $\mathrm{N}^{\mathrm{G}}$-nitro-Larginine methyl ester (L-NAME) (Kroller-Schon et al., 2018; Steven et al., 2020; Frenis et al., 2021). The paradoxical increase in eNOS protein expression and activating Ser1177 phosphorylation in mice exposed to 4 days of aircraft noise can be best explained by the presence of a largely uncoupled eNOS enzyme. Upregulation of an uncoupled eNOS and increased Ser1177 phosphorylation of an uncoupled eNOS would be detrimental through enhanced superoxide, largely compatible with the observed diminished NO bioavailability (Munzel et al., 2017; Kroller-Schon et al., 2018). However, we also found a reduction in activating phosphorylation at Ser1177 in hypertensive mice who were also exposed to 7 days of noise [mean $72 \mathrm{~dB}(\mathrm{~A})$ ] (Steven et al., 2020). Since oxidative stress was normalized in noise-exposed mice with Nox2 deletion (KrollerSchon et al., 2018), it is presumptive that extinguishing the initiating spark of superoxide production from Nox2 was sufficient to prevent the uncoupling of eNOS in these mice. In the brains of noise-exposed mice, however, $\mathrm{nNOS}$ appeared to be downregulated and uncoupled, which was also preventable through the deletion of Nox2 (Kroller-Schon et al., 2018). In addition, we found eNOS S-glutathionylation in aorta and heart of noise exposed mice (Munzel et al., 2017) that was normalized in Nox2 knockout mice (Kroller-Schon et al., 2018) and was aggravated in an additive manner in noise-exposed hypertensive mice (Steven et al., 2020). Increased eNOS phosphorylation at 


\section{A}

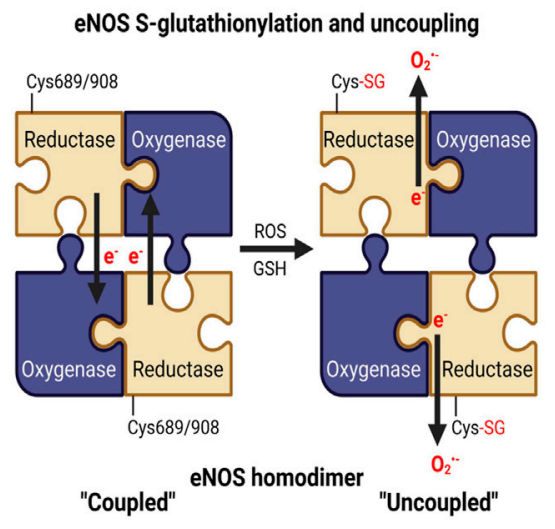

B

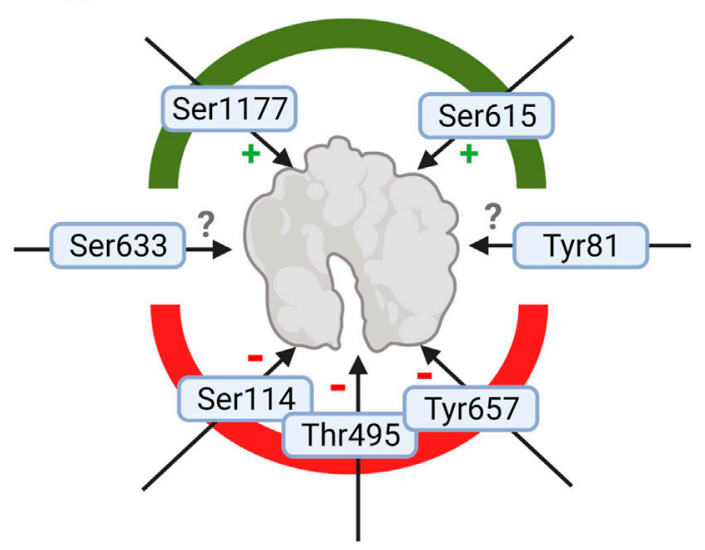

FIGURE 3|Adverse regulation of eNOS function by noise. (A) Schematic explanation of increased eNOS S-glutathionylation in mouse tissues (a surrogate marker for uncoupling of the protein) upon noise exposure (Munzel et al., 2017; Kroller-Schon et al., 2018; Steven et al., 2020). In the "coupled" eNOS homodimer, electrons are usually transferred from the NADPH and flavins to the hem iron. Cysteine residues 689 and/or 908 undergo S-glutathionylation with structural changes (Chen et al., 2010), followed by misdirection of the electrons to molecular oxygen and superoxide formation, termed "uncoupled" state of eNOS. (B) eNOS activity is regulated by various kinase-dependent modifications such as activating phosphorylation at serine 1177 or Ser615 and inactivating ones at serine 114 , threonine 495 (or 497 depending on the species) and tyrosine 657 (Fleming and Busse, 2003; Mount et al., 2007). Although pThr495-and pTyr657-eNOS was not reported for noise exposure, these inactivating phosphorylations may be expected since they are mediated by oxidatively activated kinases (PKC and PYK-2). Whereas higher eNOS protein expression and Ser1177 phosphorylation was observed in noise (4d)-exposed mice indicating counterregulatory upregulation and activating modification to rescue uncoupling of eNOS enzyme (Munzel et al., 2017; Kroller-Schon et al., 2018), suppression of pSer1177-eNOS was observed in noise-exposed hypertensive mice exposed to 7 days of noise (Steven et al., 2020). Other eNOS phosphorylation sites are not completely explored with respect to their functional effects (Ser633 and Tyr81). Image was created using Biorender.com.

Thr495 or Tyr657 in response to noise exposure was so far not reported but could be expected due to the redox-sensitivity of the kinases PKC and PYK-2 that confer these phosphorylations. Monomerization of eNOS due to zinc-sulfur complex oxidation in noise-exposed animals was so far also not observed.

\section{Noise Causes Down-Regulation, Inactivation and Uncoupling of nNOS}

In our own studies, noise exposure of mice resulted in decreased nNOS protein expression and triggered uncoupling of nNOS in cerebral tissue. Noise caused phosphorylation of nNOS at serine 847 (Kroller-Schon et al., 2018), which was previously reported to be associated with inhibited (Komeima et al., 2000) or even uncoupled nNOS enzyme (Kasamatsu et al., 2014). Of note, phosphorylation at serine 847 of nNOS is mediated by the redox sensitive calcium/calmodulin-dependent protein kinase (Kasamatsu et al., 2014). The oxidative stress signal in brains of noise-exposed mice could be also partially blocked by specific inhibition of nNOS by ARL-17477, which was in support of nNOS-derived ROS generation and compatible with uncoupling of nNOS enzyme (Kroller-Schon et al., 2018). Oxidative depletion of the protective neurotransmitter ${ }^{\circ} \mathrm{NO}$ also provides an explanation for the observed noise-induced neuroinflammatory phenotype, loss of the protective antioxidant transcription factor Foxo3, all of which contributes to the noise-induced cerebral oxidative stress (Kroller-Schon et al., 2018; Frenis et al., 2021). In addition, suppression of nNOS signaling and shift to a prooxidative/inflammatory phenotype of noise-exposed brains provides a feasible explanation for impairment of cognitive development (memory/learning) of school children exposed to high noise levels (Stansfeld et al., 2005). In line with this, impaired learning and memory in adult rats was also found to be associated with Nox2 activity (Kan et al., 2015).

\section{Noise Upregulates Endothelin-1 That Activates Nox2 and Vice Versa}

We also found induction of endothelin-1 expression in the aorta of noise-exposed mice and also exacerbation of endothelin-receptor signaling as envisaged by more pronounced endothelin-1 dependent vasoconstriction (Munzel et al., 2017; Kroller-Schon et al., 2018). Importantly, endothelin-1 is not only one of the most potent endogenous vasoconstrictors but also a potent activator of Nox2 activity, by induction of gene expression (Duerrschmidt et al., 2000; Chen et al., 2012) and direct endothelin-receptor-dependent NADPH oxidase derived ROS formation-demonstrated by $e x$ vivo stimulation with endothelin-1 or ROS suppression by $\mathrm{ET}_{\mathrm{A}}$-receptor blockade of vascular cells (Cerrato et al., 2012; Chen et al., 2012; Steven et al., 2018) or white blood cells (Steven et al., 2017). Endothelin-1 triggered NADPH oxidase-dependent ROS formation was also observed in different models of hypertension (Li et al., 2003a; Li et al., 2003b; Li et al., 2003c). Vice versa, it is also well established that oxidative stress conditions in general and Nox2derived ROS formation in particular may increase the activity of the endothelin-1 promoter and thereby increase endothelin-1 expression (Kahler et al., 2000; Kahler et al., 2001). Given the cross-activation of Nox2 and endothelin-1, the stimulation of either pathway may lead to 
a vicious circle that contributes significantly to the cardiovascular oxidative stress and damage (Daiber et al., 2017a). Mitochondrial ROS can also stimulate the release of endothelin-1 as shown in pulmonary artery cells (Ouyang et al., 2012). Endothelin-1 shares also several cross-activation mechanisms with the renin-angiotensinaldosterone system as evident from higher endothelin-1 expression levels in angiotensin-II treated hypertensive rats (Rajagopalan et al., 1997) and by decreased blood pressure as well as lower plasma angiotensin-II levels in hypertensive animals with bosentan $\left(\mathrm{ET}_{\mathrm{A} / \mathrm{B}}\right.$ receptor blocker) therapy (Tran et al., 2009). Noise-driven reninangiotensin-aldosterone system activation by stress hormones can lead to endothelin-1 upregulation or vice versa noise-triggered oxidative stress can stimulate endothelin-1 release and subsequently higher renin-angiotensin-aldosterone system activity. By these mechanisms, endothelin-1 may also contribute to the pronounced toxic effects of noise on Alport $\left(\mathrm{Col}_{4} \mathrm{a}^{-/-}\right)$mice who display glomerular dysfunction and hearing loss (Meehan et al., 2016).

\section{OTHER NOISE-INDUCED PATHWAYS THAT AFFECT SYSTEMIC REDOX PROCESSES OR ARE AFFECTED BY OXIDATIVE STRESS}

\section{Noise and the Circadian System}

The circadian clock regulates a number of essential biological functions such as sleep, body temperature, appetite, cognitive functions via time-dependent hormone release such as cortisol or melatonin (Van Laake et al., 2018). Circadian disruption has been identified as a risk factor for cardiovascular disease independently of noise (Crnko et al., 2019), but has also been associated with high (night-time) noise exposure burden (Eze et al., 2017; Munzel et al., 2020; Munzel et al., 2021a) or disrupted sleep pattern such as in shift workers (Furlan et al., 2000; Morris et al., 2016; Thosar et al., 2018). Importantly, given the context of the previous sections detailing the importance of oxidative stress in the adverse effects of noise exposure, redox mechanisms have also been implicated as important in the "redox control of cellular timekeeping” (Putker and O'Neill, 2016). Direct redox modifications of circadian components cryptochrome (CRY), period (PER), and F-box/leucine rich-repeat protein 3 (FBXL3) arise as thiol oxidation/reduction and the formation or disruption of zinc-sulfur complexes, which then control the binding of these components to the regulators circadian locomotor output cycles protein kaput (CLOCK) and brain and muscle Arnt-like protein 1 (BMAL1) complex, an essential part of the feedback mechanism inherent to circadian control (Figure 4) (Schmalen et al., 2014). While the direct redox modifications of clock components in the context of noise exposure have yet to be realized, other regulatory redox mechanisms also exist. Redox-sensitive kinases, histone deacteylases, stress-response proteins, and transcription factors can be modulated by the presence of ROS with further impact on the clock system (Figure 4) (Li et al., 2019a). The impact of various environmental stressors, including mental/social

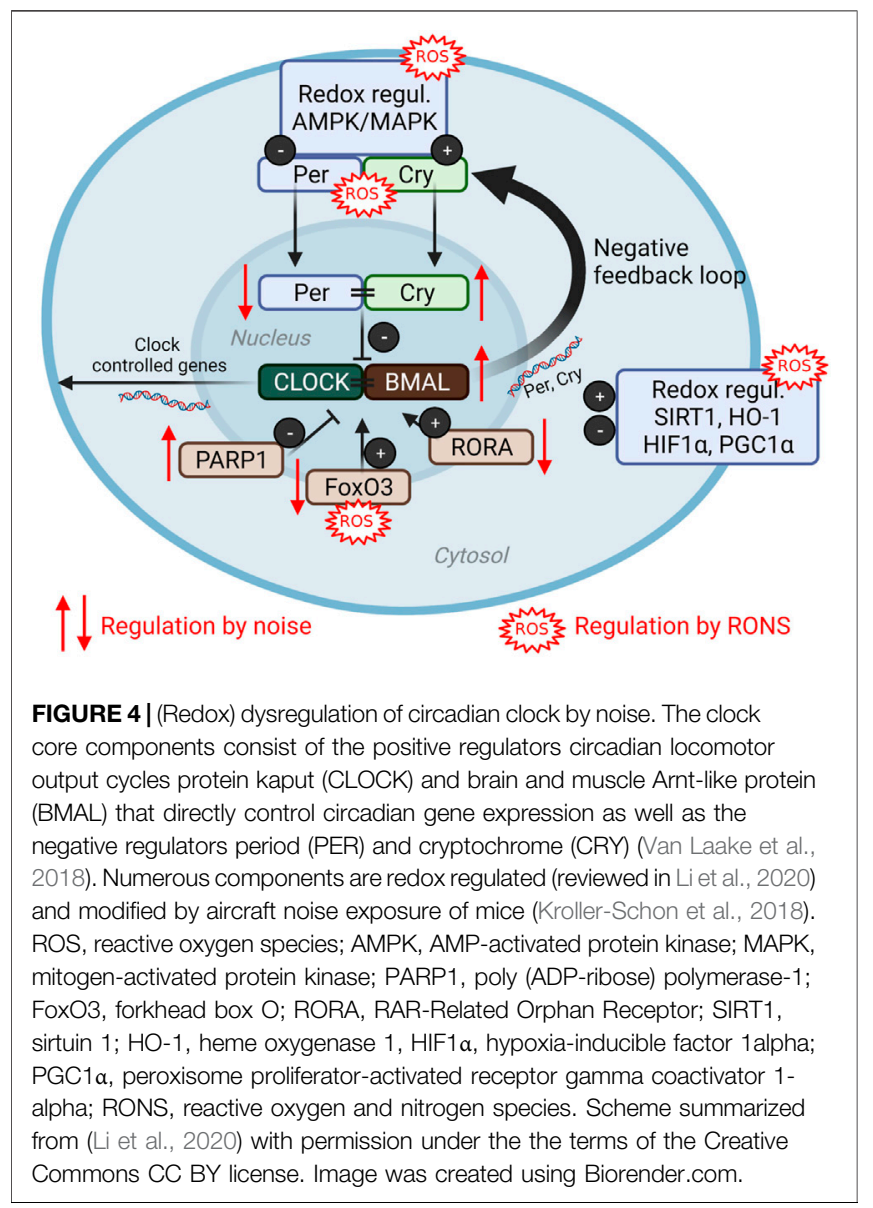

isolation stress, air pollution, heavy metals and pesticides on the circadian clock, especially its adverse redox regulation, was reviewed in (Li et al., 2020).

Bridging the concepts of circadian disruption by noise and redox control of the clock system, there is evidence of an important role in environmental cues and stressors in the regulation of the circadian rhythm ( $\mathrm{Li}$ et al., 2019a). In mice exposed to continuous aircraft noise for 4 days [mean sound pressure level (SPL) of $72 \mathrm{~dB}(\mathrm{~A})]$, expression patterns of key components of the circadian pathway in aorta and kidney were altered in comparison to unexposed controls (Kroller-Schon et al., 2018), including downregulation of Per1 and REV-ERB$\alpha / \beta(\mathrm{Nr} 1 \mathrm{~d} 1 / 2)$ or ROR $\alpha$ and upregulation of Bmal1, Cry1, Cul1, Prkag1/2, Parp1. In total, more than 30 circadian genes were altered in their expression levels. Downregulation of forkheadbox-protein $\mathrm{O} 3$ (FoxO3), a transcription factor that seemed to function as a central signalling hub regulating the circadian genes in the vascular tissue, was also reported. Pharmacological activation of FoxO3 by bepridil successfully prevented noiseinduced oxidative stress in the aorta and the endothelial dysfunction that arises from it (Kroller-Schon et al., 2018). In a study of the transcriptomics of neurons within the inferior colliculus, a brain structure that has an important role in sound processing, distinct profiles between day and night-time exposure appeared in clock genes (Park et al., 2016). 


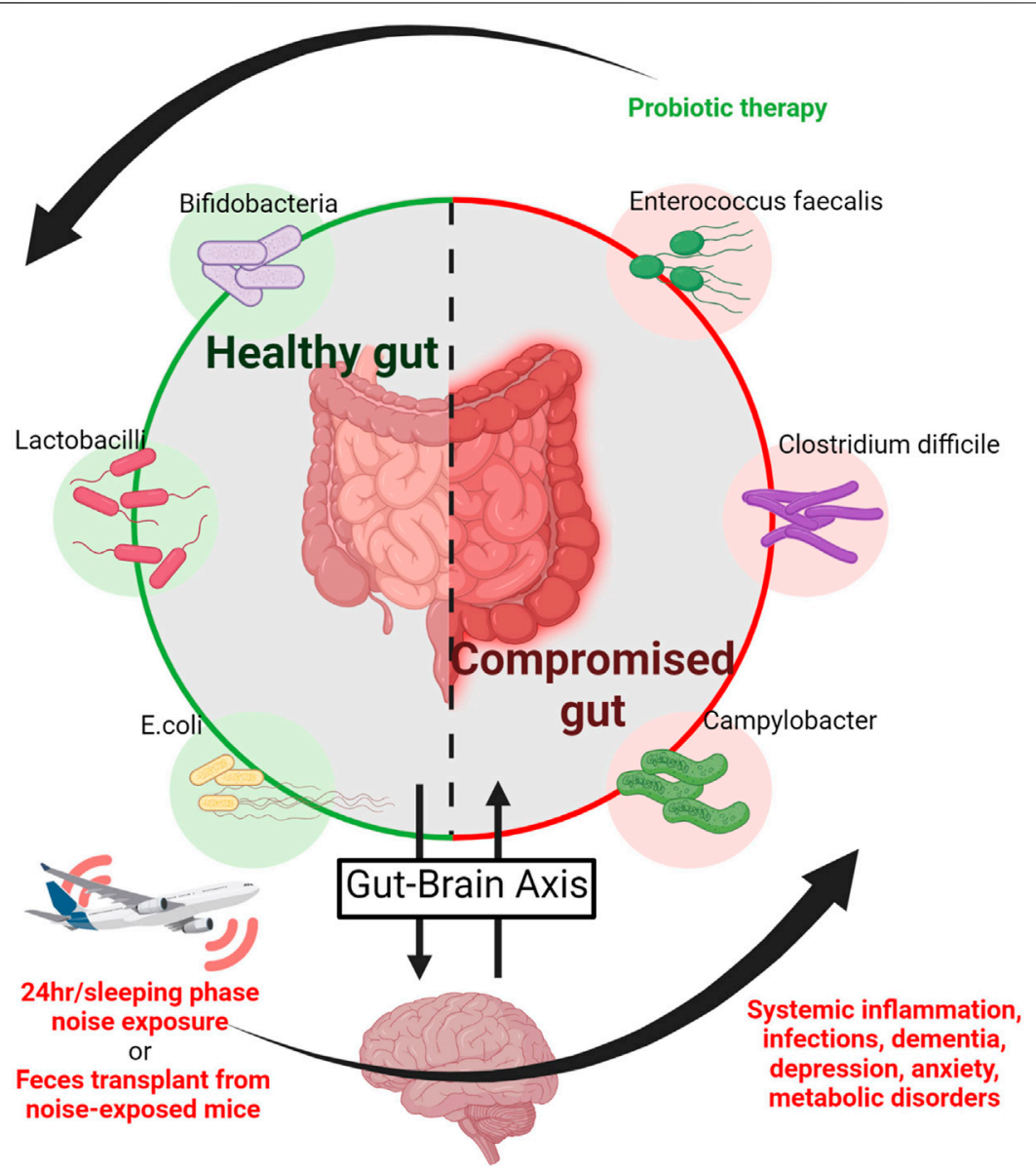

FIGURE $\mathbf{5}$ | Noise and the microbiome. The gastro-intestinal microbiome is connected to neuropsychiatric processes via the gut-brain axis and thereby affects neuropsychiatric disorders, whereas mood and neuropsychiatric health may affect intestinal inflammatory disease (Collins et al., 2012; Cryan and Dinan, 2012). Noise causes neuronal activation with subsequent stress hormone release and is associated with annoyance, depression and dementia. Accordingly, noise triggers alterations of the gut-brain axis leading to a shift to harmful bacteria in the intestine associated with cognitive impairment and A $\beta$ accumulation in a murine model of Alzheimer's disease (Cui et al., 2018). Noise also disrupts the equilibrium of intestinal pro-oxidative and antioxidant mechanisms in association with low-grade systemic inflammation in mice (Chi et al., 2021) and generally causes an imbalance of health-compromising versus -promoting bacteria together with impaired mental health. As a proof-ofconcept these adverse health effects of noise where mostly corrected by probiotic therapy (Hadizadeh et al., 2019), whereas feces transplantation from noise-exposed to unexposed mice induced the above mentioned health complications (Cui et al., 2018). Image was created using Biorender.com by modifying the central scheme from https://de.freepik.com/vektoren-premium/menschlicher-doppelpunktvektor-der-guten-bacterial-flora-illustration_3804027.htm.

\section{Noise and the Microbiome}

The investigation of gut microbiota in the pathomechanisms of disease has experienced an explosion in recent years. The microbiome affects fundamental processes such as inflammation and redox signalling in the gastro-intestinal tract (Figure 5) (Campbell and Colgan, 2019). As a result, significant associations between the state of gut microbiota and cardiometabolic diseases have been made (Jones and Neish, 2017; Campbell and Colgan, 2019). Additionally, the existence of a gut-brain axis appears to be a central player for mood and behavior regulation as well as for the development of neuropsychiatric disorders and intestinal inflammatory disease (Collins et al., 2012; Cryan and Dinan, 2012). This may also be of particular interest for the present review as transportation noise is obviously also associated with a higher incidence of all-cause dementia, namely Alzheimer's disease (Cantuaria et al., 2021).
These states are noteworthy in the current context due to their known cardiovascular and mental risk (Hahad et al., 2019). Relatively few studies explicitly probe the relationship between noise exposure and alterations of the gut microbiome, but those that have been conducted show notable effects of noise. In one study of chronic exposure for $4 \mathrm{~h} / \mathrm{d}$ during the sleeping phase over the course of 30 days [88-98 $\mathrm{dB}(\mathrm{A})$ ], alterations of the microbiome-gut-brain axis were reported (Cui et al., 2018). The mice of the study were a model for Alzheimer's disease, and chronic noise exposure was associated with cognitive impairment and amyloid beta peptide (A $\beta)$ accumulation. The mice correspondingly had decreased neurotransmitter levels (5-HT and GABA), increased markers of neuroinflammation, and impaired intestinal and brain endothelial tight junction protein expression (e.g., claudins and occludin). Underlying these changes, alterations of the intestinal flora were revealed by $16 \mathrm{~S}$ ribosomal RNA sequencing, which was supported by 
additional experiments utilizing fecal transplantation (Figure 5). Feces from mice exposed to $98 \mathrm{~dB}(\mathrm{~A})$ noise were transplanted into unexposed mice, who subsequently developed an Alzheimerlike phenotype (Cui et al., 2018). Changes in the gut microbiome in a mouse model for Alzheimer's disease were associated with an imbalance between intestinal pro-oxidative and antioxidant pathways as well as low-grade systemic inflammation in response to noise exposure (Chi et al., 2021).

Results of altered gut composition were also reported for noiseexposed rats in a similar experimental exposure (Cui et al., 2016), as well as an alteration in the balance of health-compromising proteobacteria and health-promoting actinobacteria as measured by $16 \mathrm{~S}$ rRNAseq (Zymantiene et al., 2017). These noise-induced changes in microbial balance were accompanied by increased TNF- $\alpha$ and IL- $1 \beta$ as well as alterations of body weight, and haematological parameters as well as histopathological changes in the organs (Zymantiene et al., 2017). Anxiety-like behavior arose following noise exposure in rats, where higher serum corticosterone levels reflecting the increased stress response. Probiotic treatment alleviated these symptoms by apparently restoring the gut-brain axis (Figure 5) (Hadizadeh et al., 2019). Though the data up until now is rather sparse, these early findings indicate that noise disruption of the gutbrain axis through disturbance of the gut microbiota could be exacerbating the inflammatory phenotype that arises following noise exposure, which could potentially lead to cardiometabolic disease development (Karl et al., 2018).

\section{Noise and Metabolic Syndrome}

Metabolic syndrome comprises a cluster of co-occurring conditions which lead to or complicate cardiometabolic disease. These conditions include hypertension, hyperglycemia, insulin resistance, dyslipidemia, type 2 diabetes, nonalcoholic fatty liver disease, and dementia. These conditions are all associated with oxidative stress via the increased production of ROS (Spahis et al., 2017a; Spahis et al., 2017b; Carrier, 2017). Notably, metabolic syndrome has known associations with the two modes of disturbance outlined in the noise reaction scheme: sleep and stress. Metabolic syndrome has a positive correlation with both abnormal sleep patterns, such as overly long or short duration (Smiley et al., 2019), sleep apnea (Borel, 2019), as well as circadian disruptions (Depner et al., 2014).

While we are unaware of any translational animal studies explicitly investigating metabolic syndrome as a cluster, there are several studies in mice and rats that focus on type 2 diabetes and insulin resistance. One such study found that diabetes induced by high fat diet was worsened by merely $4 \mathrm{~h} / \mathrm{d}$ of $85 \mathrm{~dB}$ SPL noise exposure, as measured through glucose intolerance, insulin resistance, fasting hyperglycemia, and apparent dyslipidemia (Liu et al., 2018b). Another study found that in male mice, $4 \mathrm{~h} / \mathrm{d}$ of $95 \mathrm{~dB}$ SPL noise exposure caused insulin resistance accompanied by phosphorylation of Akt, IRS1, and JNK, increased levels of circulating inflammatory cytokines TNF- $\alpha$ and IL6, and increased SOD and catalase activity, indicative of oxidative stress (Liu et al., 2018a). Insulin resistance was also documented in noise exposure of 1,10 , and 20 days (Liu et al., 2016). Rats exposed to 28 days of $95 \mathrm{~dB}$ noise were also found to have increased corticosterone, triglycerides, total cholesterol, and altered the balance of lipoproteins (Morakinyo et al., 2019). These findings are also in agreement with observational studies on the prevalence and incidence of metabolic syndrome conducted in humans, both during occupational and other noise exposures (Huang et al., 2020; Khosravipour et al., 2020; Yu et al., 2020). Road traffic noise was also associated with incident diabetes in the population-based Danish Diet, Cancer and Health cohort comprising 57,053 participants (Sorensen et al., 2013). Overall, there is evidence of a possible link between high noise exposure and several components of metabolic syndrome, with a possible mechanistic link through stress and sleep disruption prompting the production of ROS, though more investigation is certainly required.

\section{Noise and Epigenetic Pathways}

Epigenetic changes can modulate the development and progression as well as the severity of cardiovascular diseases by control of atherosclerotic processes (Ordovas and Smith, 2010; Kuznetsova et al., 2020). Epigenetic processes are largely redox-regulated (Mikhed et al., 2015; Kietzmann et al., 2017; Leisegang et al., 2017) and thereby noise-induced oxidative stress will most likely change the epigenetic landscape at multiple layers. We and others reported noise-induced changes of coding RNA by next-generation sequencing in models of non-auditory noise effects (Munzel et al., 2017; Kroller-Schon et al., 2018) and studies on hearing loss (Wei et al., 2020; Lavinsky et al., 2021). However, noise exposure, sleep deprivation and mental stress can also lead to altered expression patterns of non-coding RNA, e.g., in microRNAs that have significant health impact (Miguel et al., 2018; Miguel et al., 2020). The dysregulation of microRNAs can be mediated by the indirect pathway, e.g., the known stress response, but also via direct mechanical damage of the inner ear during hearing loss (Miguel et al., 2018). Higher expression levels of miR-134/183 in the central amygdala were observed after acute stress exposure (Meerson et al., 2010). Both microRNAs seem to have significant health impact as they were found at higher concentrations in patients with coronary artery disease and depression. Numerous of these microRNAs that are associated with environmental risk factors such as noise exposure or mental stress are either regulated by oxidative stress or themselves influence gene transcription encoding for antioxidant defense or pro-oxidative proteins (Miguel et al., 2018; Miguel et al., 2020). Methylation of DNA bases is another epigenetic regulatory process with large impact on cardiovascular risk (Greco and Condorelli, 2015). Alterations of the DNA methylome, the sum of all methylated DNA bases with significant effect on transcriptional activity of DNA, were demonstrated in the brain of rats after chronic noise exposure, pointing towards epigenetic regulation of metabolic pathways by stress signalling in the form of noise exposure (Guo et al., 2017). Of note, a cohort study (SAPALDIA) conducted in Switzerland found an association between long-term exposure to transportation noise and DNA methylation patterns indicating activation of inflammatory pathways, alterations of cellular development and changes of immune responses (Eze et al., 2020). Epigenetic effects observed by human and animal studies on hearing loss but also 
epigenetic changes in non-auditory models were reviewed in (Leso et al., 2020).

\section{CONCLUSION}

In conclusion, noise is a somewhat "pleiotropic" stressor, with the ability to incur damage through both cognitive and noncognitive input pathways. Cognition of noise, as happens during noise exposure while awake, appears to be linked to the anxiety and depression, as reported following noise exposure in humans. These symptoms in humans correspond well with a neuroinflammatory phenotype stemming from both astrocytic and microglial activation in mice, accompanied by downregulation and uncoupling of nNOS. Critically, noise exposure also activates both the SNS and HPA axis, causing hormonal dysregulation, which can inflict changes in the peripheral systems. Studies in mice suggest that these hormonal disruptions coupled with circadian interruption promote the production of oxidative stress, which appears to be the common thread through all the detrimental effects of noise and seems to be largely based on Nox2 activation as the major source of ROS. In short, infiltration of monocytes and macrophages in response to stress appears to trigger the production of oxidative stress, which then uncouples e/nNOS via specific redox switches, disrupts nitric oxide signaling, disturbs essential phosphorylation within circadian pathways, and activates ROS-sensitive transcription factor NFkB as well as defense systems such as Nrf2/HO-1 or causes impairment of FoxO3 signaling. These effects also have potential for affecting epigenetic regulation and microbiome homeostasis. Because of the importance of these effects for affecting human health, it is necessary for noise research to be conducted in a systemized manner in both humans and animals to explore both the unknowns in redox and cardiovascular biology, but also those in other fields.

\section{FUTURE DIRECTIONS}

The molecular underpinnings of noise-induced physiological consequences appear as a consequence of hormonally-induced hyperactivity of cells of the monocytic line bearing Nox2. Cellular metabolic changes are not only important in cardiovascular research, but also in several other fields of study, including cancer and neurological disorders. Given that the effects in the brain are so notable in translational work and behavioral and emotional effects are apparent in humans, there appears to be a wide field of study in the effects of noise within both the cerebrovasculature and in directly studying neuronal health. Since mice have thus far been a relatively faithful model for at least one mode of noise exposure, translational studies investigating the behavioral and cognitive effects of noise are warranted. Our own work suggests that there is a combinatorial effect between pre-existing hypertension and noise exposure, which worsens the phenotype. Additional study into the effects of noise in other disease states appears to have potential for linking the exposome to tangible effects on human health.

\section{LIMITATIONS}

Though the field of noise research is quickly expanding, the major limitation remains to be a paucity of mechanistic studies. Most of the investigations in humans are through the lens of occupational exposure to noise, which is often high-intensity and acute, whereas the majority of people are exposed in lower levels in their daily life (i.e., through ambient traffic noise). While the consensus that very high exposure has links to metabolic and cardiovascular consequences, more and better standardized studies are required to investigate the everyday noise burden, especially at a mechanistic level on-top of the so far mostly observational epidemiological studies that focus on the overall health impact (e.g., disease incidence and prevalence). Another significant limitation is the variance in exposure: each individual's daily exposure will vary, which complicates observational studies in human communities. Though mouse models can replicate the consequences of noise in some aspects, it is unlikely that mice can feel the depth of emotional response a human would to an unwelcome noise, meaning that translational research can only reflect one half of the noise-reaction scheme and that the noise in these experiments is probably imparting its effects through sleep disruption. This may be overcome by technical advances in the field of personal monitoring devices, which would allow continuous recording of the noise exposure levels of the individual during daily life. Lastly, it is notable that the majority of translational studies are conducted in male mice, which is useful for lower variation range of the data but may not accurately reflect the range of response to a stressor such as noise that is largely affected by alterations of hormonal pathways that are known to show significant differences between males and females.

\section{AUTHOR CONTRIBUTIONS}

$\mathrm{KF}, \mathrm{MK}$, and $\mathrm{AD}$ drafted most part of the MS and created the figures and proofread the final MS and made critical revisions in the text and in the figures. $\mathrm{OH}, \mathrm{MB}$, and $\mathrm{MO}$ helped to produce the figures and made critical revisions of the MS. SD, and SS drafted specific sections/paragraphs of the MS. TM proofread the final MS and made critical revisions in the text and in the figures.

\section{FUNDING}

$\mathrm{AD}$, SS, and TM were supported by vascular biology research grants from the Boehringer Ingelheim Foundation for the collaborative research group "Novel and neglected 
cardiovascular risk factors: molecular mechanisms and therapeutics." Further support was provided by the ElseKröner Fresenius Foundation (2019_A110 to SD and 2017_A106 to SS), the German Heart Foundation/German Foundation of Heart Research (F/51/19 to SD) and the Foundation Heart of Mainz (continuous support to AD, OH,

\section{REFERENCES}

Antunes, E., Borrecho, G., Oliveira, P., Alves De Matos, A. P., Brito, J., Águas, A., et al. (2013a). Effects of Low-Frequency Noise on Cardiac Collagen and Cardiomyocyte Ultrastructure: an Immunohistochemical and Electron Microscopy Study. Int. J. Clin. Exp. Pathol. 6, 2333-2341.

Antunes, E., Borrecho, G., Oliveira, P., Brito, J., Águas, A., and Martins Dos Santos, J. (2013b). Immunohistochemical Evaluation of Cardiac Connexin43 in Rats Exposed to Low-Frequency Noise. Int. J. Clin. Exp. Pathol. 6, 1874-1879.

Antunes, E., Oliveira, P., Borrecho, G., Oliveira, M. J. R., Brito, J., Águas, A., et al. (2013c). Myocardial Fi Brosis in Rats Exposed to Low Frequency Noise. Acta Cardiologica 68, 241-245. doi:10.1080/ac.68.3.2983417

Arpornchayanon, W., Canis, M., Ihler, F., Settevendemie, C., and Strieth, S. (2013). TNF- $\alpha$ Inhibition Using Etanercept Prevents Noise-Induced Hearing Loss by Improvement of Cochlear Blood Flow In Vivo. Int. J. Audiol. 52, 545-552. doi:10.3109/14992027.2013.790564

Babisch, W. (2002). The Noise/Stress Concept, Risk Assessment and Research Needs. Noise Health 4, 1-11.

Babisch, W., Ising, H., Gallacher, J. E. J., and Elwood, P. C. (1988). Traffic Noise and Cardiovascular Risk. The Caerphilly Study, First Phase. Outdoor Noise Levels and Risk Factors. Arch. Environ. Health Int. J. 43, 407-414. doi:10.1080/ 00039896.1988.9935859

Baldwin, A. L., and Bell, I. R. (2007). Effect of Noise on Microvascular Integrity in Laboratory Rats. J. Am. Assoc. Lab. Anim. Sci. 46, 58-65.

Bauer, R., Gerhardt, K. J., Abrams, R. M., Huang, X., and Bauer, K. (2001). Effects of Impulse Noise Stimulation on Electrocorticogram and Heart Rate. Neonatology 79, 113-121. doi:10.1159/000047077

Bayo Jimenez, M. T., Frenis, K., Kröller-Schön, S., Kuntic, M., Stamm, P., Kvandová, M., et al. (2021). Noise-Induced Vascular Dysfunction, Oxidative Stress, and Inflammation Are Improved by Pharmacological Modulation of the NRF2/HO-1 Axis. Antioxidants 10, 625. doi:10.3390/antiox10040625

Beutel, M. E., Brähler, E., Ernst, M., Klein, E., Reiner, I., Wiltink, J., et al. (2020). Noise Annoyance Predicts Symptoms of Depression, Anxiety and Sleep Disturbance 5 Years Later. Findings from the Gutenberg Health Study. Eur. J. Public Health 30, 487-492. doi:10.1093/eurpub/ckaa015

Beutel, M. E., Jünger, C., Klein, E. M., Wild, P., Lackner, K., Blettner, M., et al. (2016). Noise Annoyance Is Associated with Depression and Anxiety in the General Population- the Contribution of Aircraft Noise. PLoS One 11, e0155357. doi:10.1371/journal.pone.0155357

Borel, A.-L. (2019). Sleep Apnea and Sleep Habits: Relationships with Metabolic Syndrome. Nutrients 11, 2628. doi:10.3390/nu11112628

Borg, E., and Järplid, B. (1981). Life Span and Organ Pathology in Rats after LifeLong Noise Exposure. Am. J. Ind. Med. 2, 353-363. doi:10.1002/ ajim. 4700020406

Breschi, M. C., Martini, C., Scatizzi, R., Cristofani, R., Giannaccini, G., Martinotti, E., et al. (1995). Benzodiazepine Agonists Reverse the Effects of Noise Exposure on central Benzodiazepine Receptors and Cardiac Responsiveness. Life Sci. 57, 1131-1140. doi:10.1016/0024-3205(95)02058-q

Cai, Y., Hansell, A. L., Blangiardo, M., Burton, P. R., de HooghDe Hoogh, K., Doiron, D., et al. (2017). Long-term Exposure to Road Traffic Noise, Ambient Air Pollution, and Cardiovascular Risk Factors in the HUNT and Lifelines Cohorts. Eur. Heart J. 38, 2290-2296. doi:10.1093/eurheartj/ehx263

Campbell, E. L., and Colgan, S. P. (2019). Control and Dysregulation of Redox Signalling in the Gastrointestinal Tract. Nat. Rev. Gastroenterol. Hepatol. 16, 106-120. doi:10.1038/s41575-018-0079-5

Cantuaria, M. L., Waldorff, F. B., Wermuth, L., Pedersen, E. R., Poulsen, A. H., Thacher, J. D., et al. (2021). Residential Exposure to Transportation Noise in
SS, and SD). Our research was continuously supported by the European Cooperation in Science and Technology and EUCARDIOPROTECTION COST-ACTION (CA16225), a funding scheme to enhance scientific networking in Europe. TM is PI of the DZHK (German Center for Cardiovascular Research), Partner Site Rhine-Main, Mainz, Germany.

Denmark and Incidence of Dementia: National Cohort Study. BMJ 374, n1954. doi:10.1136/bmj.n1954

Carrier, A. (2017). Metabolic Syndrome and Oxidative Stress: A Complex Relationship. Antioxid. Redox Signaling 26, 429-431. doi:10.1089/ars.2016.6929

Cerrato, R., Cunnington, C., Crabtree, M. J., Antoniades, C., Pernow, J., Channon, K. M., et al. (2012). Endothelin-1 Increases Superoxide Production in Human Coronary Artery Bypass Grafts. Life Sci. 91, 723-728. doi:10.1016/ j.lfs.2012.03.024

Chan, S.-L., and Baumbach, G. L. (2013). Nox2 Deficiency Prevents HypertensionInduced Vascular Dysfunction and Hypertrophy in Cerebral Arterioles. Int. J. Hypertens. 2013, 1-8. doi:10.1155/2013/793630

Chen, C.-A., Wang, T.-Y., Varadharaj, S., Reyes, L. A., Hemann, C., Talukder, M. A. H., et al. (2010). S-glutathionylation Uncouples eNOS and Regulates its Cellular and Vascular Function. Nature 468, 1115-1118. doi:10.1038/ nature09599

Chen, D.-D., Dong, Y.-G., Yuan, H., and Chen, A. F. (2012). Endothelin 1 Activation of Endothelin A receptor/NADPH Oxidase Pathway and Diminished Antioxidants Critically Contribute to Endothelial Progenitor Cell Reduction and Dysfunction in Salt-Sensitive Hypertension. Hypertension 59, 1037-1043. doi:10.1161/ HYPERTENSIONAHA.111.183368

Chi, H., Cao, W., Zhang, M., Su, D., Yang, H., Li, Z., et al. (2021). Environmental Noise Stress Disturbs Commensal Microbiota Homeostasis and Induces OxiInflammmation and AD-like Neuropathology through Epithelial Barrier Disruption in the EOAD Mouse Model. J. Neuroinflammation 18, 9. doi:10.1186/s12974-020-02053-3

Clark, C., and Paunovic, K. (2018). WHO Environmental Noise Guidelines for the European Region: A Systematic Review on Environmental Noise and Quality of Life, Wellbeing and Mental Health. Ijerph 15, 2400. doi:10.3390/ijerph15112400

Collins, S. M., Surette, M., and Bercik, P. (2012). The Interplay between the Intestinal Microbiota and the Brain. Nat. Rev. Microbiol. 10, 735-742. doi:10.1038/nrmicro2876

Crnko, S., Du Pré, B. C., Sluijter, J. P. G., and Van Laake, L. W. (2019). Circadian Rhythms and the Molecular Clock in Cardiovascular Biology and Disease. Nat. Rev. Cardiol. 16, 437-447. doi:10.1038/s41569-019-0167-4

Cryan, J. F., and Dinan, T. G. (2012). Mind-altering Microorganisms: the Impact of the Gut Microbiota on Brain and Behaviour. Nat. Rev. Neurosci. 13, 701-712. doi:10.1038/nrn3346

Cui, B., Gai, Z., She, X., Wang, R., and Xi, Z. (2016). Effects of Chronic Noise on Glucose Metabolism and Gut Microbiota-Host Inflammatory Homeostasis in Rats. Sci. Rep. 6, 36693. doi:10.1038/srep36693

Cui, B., Su, D., Li, W., She, X., Zhang, M., Wang, R., et al. (2018). Effects of Chronic Noise Exposure on the Microbiome-Gut-Brain axis in Senescence-Accelerated Prone Mice: Implications for Alzheimer's Disease. J. Neuroinflammation 15, 190. doi:10.1186/s12974-018-1223-4

Daiber, A., and Chlopicki, S. (2020). Revisiting Pharmacology of Oxidative Stress and Endothelial Dysfunction in Cardiovascular Disease: Evidence for RedoxBased Therapies. Free Radic. Biol. Med. 157, 15-37. doi:10.1016/ j.freeradbiomed.2020.02.026

Daiber, A., Di Lisa, F., Oelze, M., Kröller-Schön, S., Steven, S., Schulz, E., et al. (2017a). Crosstalk of Mitochondria with NADPH Oxidase via Reactive Oxygen and Nitrogen Species Signalling and its Role for Vascular Function. Br. J. Pharmacol. 174, 1670-1689. doi:10.1111/bph.13403

Daiber, A., Hahad, O., Andreadou, I., Steven, S., Daub, S., and Münzel, T. (2021) Redox-related Biomarkers in Human Cardiovascular Disease - Classical Footprints and beyond. Redox Biol. 42, 101875. doi:10.1016/ j.redox.2021.101875 
Daiber, A., Kröller-Schön, S., Frenis, K., Oelze, M., Kalinovic, S., Vujacic-Mirski, K., et al. (2019a). Environmental Noise Induces the Release of Stress Hormones and Inflammatory Signaling Molecules Leading to Oxidative Stress and Vascular Dysfunction-Signatures of the Internal Exposome. Biofactors 45, 495-506. doi:10.1002/biof.1506

Daiber, A., Kröller-Schön, S., Oelze, M., Hahad, O., Li, H., Schulz, R., et al. (2020). Oxidative Stress and Inflammation Contribute to Traffic Noise-Induced Vascular and Cerebral Dysfunction via Uncoupling of Nitric Oxide Synthases. Redox Biol. 34, 101506. doi:10.1016/j.redox.2020.101506

Daiber, A., Oelze, M., Steven, S., Kröller-Schön, S., and Münzel, T. (2017b). Taking up the Cudgels for the Traditional Reactive Oxygen and Nitrogen Species Detection Assays and Their Use in the Cardiovascular System. Redox Biol. 12, 35-49. doi:10.1016/j.redox.2017.02.001

Daiber, A., Xia, N., Steven, S., Oelze, M., Hanf, A., Kröller-Schön, S., et al. (2019b). New Therapeutic Implications of Endothelial Nitric Oxide Synthase (eNOS) Function/Dysfunction in Cardiovascular Disease. Ijms 20, 187. doi:10.3390/ ijms20010187

Dengerink, H., Miller, J., Axelsson, A., Vertes, D., and Dalfsen, P. V. (1985). The Recovery of Vascular Changes Following Brief Noise Exposure. Acta OtoLaryngologica 100, 19-25. doi:10.3109/00016488509108582

Depner, C. M., Stothard, E. R., and Wright, K. P., Jr. (2014). Metabolic Consequences of Sleep and Circadian Disorders. Curr. Diab Rep. 14, 507. doi:10.1007/s11892-014-0507-z

Dimmeler, S., Fleming, I., Fisslthaler, B., Hermann, C., Busse, R., and Zeiher, A. M. (1999). Activation of Nitric Oxide Synthase in Endothelial Cells by Aktdependent Phosphorylation. Nature 399, 601-605. doi:10.1038/21224

Duerrschmidt, N., Wippich, N., Goettsch, W., Broemme, H.-J., and Morawietz, H. (2000). Endothelin-1 Induces NAD(P)H Oxidase in Human Endothelial Cells. Biochem. Biophysical Res. Commun. 269, 713-717. doi:10.1006/bbrc.2000.2354

Eckrich, J., Frenis, K., Rodriguez-Blanco, G., Ruan, Y., Jiang, S., Bayo Jimenez, M. T., et al. (2021). Aircraft Noise Exposure Drives the Activation of white Blood Cells and Induces Microvascular Dysfunction in Mice. Redox Biol. 46, 102063. doi:10.1016/j.redox.2021.102063

European Region (2018). Environmental Noise Guidelines for the European Region. Available at: http://www.euro.who.int/en/publications/abstracts/ environmental-noise-guidelines-for-the-european-region-2018.

Eze, I. C., Jeong, A., Schaffner, E., Rezwan, F. I., Ghantous, A., Foraster, M., et al. (2020). Genome-Wide DNA Methylation in Peripheral Blood and Long-Term Exposure to Source-specific Transportation Noise and Air Pollution: The SAPALDIA Study. Environ. Health Perspect. 128, 067003. doi:10.1289/ EHP6174

Eze, I., Imboden, M., Foraster, M., Schaffner, E., Kumar, A., Vienneau, D., et al. (2017). Exposure to Night-Time Traffic Noise, Melatonin-Regulating Gene Variants and Change in Glycemia in Adults. Ijerph 14, 1492. doi:10.3390/ ijerph14121492

Fisslthaler, B., Loot, A. E., Mohamed, A., Busse, R., and Fleming, I. (2008). Inhibition of Endothelial Nitric Oxide Synthase Activity by Proline-Rich Tyrosine Kinase 2 in Response to Fluid Shear Stress and Insulin. Circ. Res. 102, 1520-1528. doi:10.1161/CIRCRESAHA.108.172072

Fleming, I., Fisslthaler, B., Dimmeler, S., Kemp, B. E., and Busse, R. (2001). Phosphorylation of $\mathrm{Thr}(495)$ Regulates $\mathrm{Ca}(2+) /$ calmodulin-dependent Endothelial Nitric Oxide Synthase Activity. Circ. Res. 88, E68-E75. doi:10.1161/hh1101.092677

Fleming, I., and Busse, R. (2003). Molecular Mechanisms Involved in the Regulation of the Endothelial Nitric Oxide Synthase. Am. J. PhysiologyRegulatory, Integr. Comp. Physiol. 284, R1-R12. doi:10.1152/ ajpregu.00323.2002

Förstermann, U., and Münzel, T. (2006). Endothelial Nitric Oxide Synthase in Vascular Disease: from Marvel to Menace. Circulation 113, 1708-1714. doi:10.1161/CIRCULATIONAHA.105.602532

Frenis, K., Helmstädter, J., Ruan, Y., Schramm, E., Kalinovic, S., Kröller-Schön, S., et al. (2021). Ablation of Lysozyme M-Positive Cells Prevents Aircraft NoiseInduced Vascular Damage without Improving Cerebral Side Effects. Basic Res. Cardiol. 116, 31. doi:10.1007/s00395-021-00869-5

Frenzilli, G., Lenzi, P., Scarcelli, V., Fornai, F., Pellegrini, A., Soldani, P., et al. (2004). Effects of Loud Noise Exposure on DNA Integrity in Rat Adrenal Gland. Environ. Health Perspect. 112, 1671-1672. doi:10.1289/ehp.7249
Fritschi, L., Brown, A. L., Kim, A., Schwela, D. H., and Kephalopoulos, S. (2011). WHO and JRC Report: Burden of Disease from Environmental Noise. Available at: https://ec.europa.eu/jrc/sites/jrcsh/files/e94888.pdf.

Furlan, R., Barbic, F., Piazza, S., Tinelli, M., Seghizzi, P., and Malliani, A. (2000). Modifications of Cardiac Autonomic Profile Associated with a Shift Schedule of Work. Circulation 102, 1912-1916. doi:10.1161/01.cir.102.16.1912

Gannouni, N., Mhamdi, A., El May, M., Rhouma, K., and Tebourbi, O. (2014). Morphological Changes of Adrenal Gland and Heart Tissue after Varying Duration of Noise Exposure in Adult Rat. Noise Health 16, 416-421. doi:10.4103/1463-1741.144424

Gannouni, N., Mhamdi, A., Tebourbi, O., El May, M., Sakly, M., and Rhouma, K. (2013). Qualitative and Quantitative Assessment of Noise at Moderate Intensities on Extra-auditory System in Adult Rats. Noise Health 15, 406-411. doi:10.4103/1463-1741.121236

Gesi, M., Lenzi, P., Fornai, F., Ferrucci, M., Soldani, P., Pellegrini, A., et al. (2002). Effects of Loud Noise Exposure on Mouse Myocardium: a Comparison with the Rat. Microsc. Res. Tech. 59, 131-135. doi:10.1002/jemt.10185

Gogokhia, N., Japaridze, N., Tizabi, Y., Pataraya, L., and Zhvania, M. G. (2021). Gender Differences in Anxiety Response to High Intensity white Noise in Rats. Neurosci. Lett. 742, 135543. doi:10.1016/j.neulet.2020.135543

Greco, C. M., and Condorelli, G. (2015). Epigenetic Modifications and Noncoding RNAs in Cardiac Hypertrophy and Failure. Nat. Rev. Cardiol. 12, 488-497. doi:10.1038/nrcardio.2015.71

Gryglewski, R. J., Palmer, R. M. J., and Moncada, S. (1986). Superoxide Anion Is Involved in the Breakdown of Endothelium-Derived Vascular Relaxing Factor. Nature 320, 454-456. doi:10.1038/320454a0

Guo, L., Li, P.-h., Li, H., Colicino, E., Colicino, S., Wen, Y., et al. (2017). Effects of Environmental Noise Exposure on DNA Methylation in the Brain and Metabolic Health. Environ. Res. 153, 73-82. doi:10.1016/ j.envres.2016.11.017

Guski, R., Schreckenberg, D., and Schuemer, R. (2017). WHO Environmental Noise Guidelines for the European Region: A Systematic Review on Environmental Noise and Annoyance. Ijerph 14, 1539. doi:10.3390/ ijerph14121539

Guzik, T. J., Sadowski, J., Guzik, B., Jopek, A., Kapelak, B., Przybyłowski, P., et al. (2006). Coronary Artery Superoxide Production and Nox Isoform Expression in Human Coronary Artery Disease. Atvb 26, 333-339. doi:10.1161/ 01.ATV.0000196651.64776.51

Hadizadeh, M., Hamidi, G. A., and Salami, M. (2019). Probiotic Supplementation Improves the Cognitive Function and the Anxiety-like Behaviors in the Stressed Rats. Iran J. Basic Med. Sci. 22, 506-514. doi:10.22038/ijbms.2019.33956.8078

Hahad, O., Beutel, M., Gori, T., Schulz, A., Blettner, M., Pfeiffer, N., et al. (2018). Annoyance to Different Noise Sources Is Associated with Atrial Fibrillation in the Gutenberg Health Study. Int. J. Cardiol. 264, 79-84. doi:10.1016/ j.ijcard.2018.03.126

Hahad, O., Daiber, A., and Münzel, T. (2021a). Heightened Amygdalar Activity Mediates the Cardiometabolic Effects of Transportation Noise Stress. Psychoneuroendocrinology 131, 105347. doi:10.1016/j.psyneuen.2021.105347

Hahad, O., Prochaska, J. H., Daiber, A., and Münzel, T. (2019). Environmental Noise-Induced Effects on Stress Hormones, Oxidative Stress, and Vascular Dysfunction: Key Factors in the Relationship between Cerebrocardiovascular and Psychological Disorders. Oxidative Med. Cell Longevity 2019, 1-13. doi:10.1155/2019/4623109

Hahad, O., Wild, P. S., Prochaska, J. H., Schulz, A., Lackner, K. J., Pfeiffer, N., et al. (2021b). Midregional Pro Atrial Natriuretic Peptide: a Novel Important Biomarker for Noise Annoyance-Induced Cardiovascular Morbidity and Mortality? Clin. Res. Cardiol. 110, 29-39. doi:10.1007/s00392-020-01645-6

Harrison, D. G., Hua Cai, H., Landmesser, U., and Griendling, K. K. (2003). The Pickering Lecture British Hypertension Society, 10th September 2002. J. Renin Angiotensin Aldosterone Syst. 4, 51-61. doi:10.3317/jraas.2003.014

Heitzer, T., Schlinzig, T., Krohn, K., Meinertz, T., and Münzel, T. (2001). Endothelial Dysfunction, Oxidative Stress, and Risk of Cardiovascular Events in Patients with Coronary Artery Disease. Circulation 104, 2673-2678. doi:10.1161/hc4601.099485

Héritier, H., Vienneau, D., Foraster, M., Eze, I. C., Schaffner, E., De Hoogh, K., et al. (2019). A Systematic Analysis of Mutual Effects of Transportation Noise and Air Pollution Exposure on Myocardial Infarction Mortality: a Nationwide 
Cohort Study in Switzerland. Eur. Heart J. 40, 598-603. doi:10.1093/eurheartj/ ehy650

Herrmann, H.-J., Rohde, H. G. E., Schulze, W., Eichhorn, C., and Luft, F. C. (1994). Effect of Noise Stress and Ethanol Intake on Hearts of Spontaneously Hypertensive Rats. Basic Res. Cardiol. 89, 510-523. doi:10.1007/BF00794951

Herzog, J., Schmidt, F. P., Hahad, O., Mahmoudpour, S. H., Mangold, A. K., Garcia Andreo, P., et al. (2019). Acute Exposure to Nocturnal Train Noise Induces Endothelial Dysfunction and Pro-thromboinflammatory Changes of the Plasma Proteome in Healthy Subjects. Basic Res. Cardiol. 114, 46. doi:10.1007/s00395-019-0753-y

Huang, T., Chan, T.-C., Huang, Y.-J., and Pan, W.-C. (2020). The Association between Noise Exposure and Metabolic Syndrome: A Longitudinal Cohort Study in Taiwan. Ijerph 17, 4236. doi:10.3390/ijerph17124236

Jones, R. M., and Neish, A. S. (2017). Redox Signaling Mediated by the Gut Microbiota. Free Radic. Biol. Med. 105, 41-47. doi:10.1016/ j.freeradbiomed.2016.10.495

Kähler, J., Ewert, A., Weckmüller, J., Stobbe, S., Mittmann, C., Köster, R., et al. (2001). Oxidative Stress Increases Endothelin-1 Synthesis in Human Coronary Artery Smooth Muscle Cells. J. Cardiovasc. Pharmacol. 38, 49-57. doi:10.1097/ 00005344-200107000-00006

Kähler, J., Mendel, S., Weckmüller, J., Orzechowski, H.-D., Mittmann, C., Köster, R., et al. (2000). Oxidative Stress Increases Synthesis of Big Endothelin-1 by Activation of the Endothelin-1 Promoter. J. Mol. Cell Cardiol. 32, 1429-1437. doi:10.1006/jmcc.2000.1178

Kan, H., Hu, W., Wang, Y., Wu, W., Yin, Y., Liang, Y., et al. (2015). NADPH Oxidase-Derived Production of Reactive Oxygen Species Is Involved in Learning and Memory Impairments in 16-Month-Old Female Rats. Mol. Med. Rep. 12, 4546-4553. doi:10.3892/mmr.2015.3894

Karbach, S., Wenzel, P., Waisman, A., Munzel, T., and Daiber, A. (2014). eNOS Uncoupling in Cardiovascular Diseases - the Role of Oxidative Stress and Inflammation. Cpd 20, 3579-3594. doi:10.2174/13816128113196660748

Karl, J. P., Hatch, A. M., Arcidiacono, S. M., Pearce, S. C., Pantoja-Feliciano, I. G., Doherty, L. A., et al. (2018). Effects of Psychological, Environmental and Physical Stressors on the Gut Microbiota. Front. Microbiol. 9. doi:10.3389/ fmicb.2018.02013

Kasamatsu, S., Watanabe, Y., Sawa, T., Akaike, T., and Ihara, H. (2014). Redox Signal Regulation via nNOS Phosphorylation at Ser847 in PC12 Cells and Rat Cerebellar Granule Neurons. Biochem. J. 459, 251-263. doi:10.1042/ BJ20131262

Kerns, E., Masterson, E. A., Themann, C. L., and Calvert, G. M. (2018). Cardiovascular Conditions, Hearing Difficulty, and Occupational Noise Exposure within US Industries and Occupations. Am. J. Ind. Med. 61, 477-491. doi:10.1002/ajim.22833

Khosravipour, M., Abdollahzad, H., Khosravi, F., Rezaei, M., Mohammadi Sarableh, H., and Moradi, Z. (2020). The Association of Occupational Noises and the Prevalence of Metabolic Syndrome. Ann. Work Expo. Health 64, 514-521. doi:10.1093/annweh/wxaa030

Kietzmann, T., Petry, A., Shvetsova, A., Gerhold, J. M., and Görlach, A. (2017). The Epigenetic Landscape Related to Reactive Oxygen Species Formation in the Cardiovascular System. Br. J. Pharmacol. 174, 1533-1554. doi:10.1111/ bph. 13792

Kirby, D., Herd, J., Hartley, L., Teller, D., and Rodger, R. (1984). Enhanced Blood Pressure Responses to Loud Noise in Offspring of Monkeys with High Blood Pressure汿. Physiol. Behav. 32, 779-783. doi:10.1016/0031-9384(84)90194-x

Komeima, K., Hayashi, Y., Naito, Y., and Watanabe, Y. (2000). Inhibition of Neuronal Nitric-Oxide Synthase by Calcium/Calmodulin-dependent Protein Kinase II $a$ through Ser847 Phosphorylation in NG108-15 Neuronal Cells. J. Biol. Chem. 275, 28139-28143. doi:10.1074/jbc.M003198200

Kröller-Schön, S., Daiber, A., Steven, S., Oelze, M., Frenis, K., Kalinovic, S., et al. (2018). Crucial Role for Nox2 and Sleep Deprivation in Aircraft Noise-Induced Vascular and Cerebral Oxidative Stress, Inflammation, and Gene Regulation. Eur. Heart J. 39, 3528-3539. doi:10.1093/eurheartj/ehy333

Kuznetsova, T., Prange, K. H. M., Glass, C. K., and De Winther, M. P. J. (2020). Transcriptional and Epigenetic Regulation of Macrophages in Atherosclerosis. Nat. Rev. Cardiol. 17, 216-228. doi:10.1038/s41569-019-0265-3

Kvandova, M., Filippou, K., Steven, S., Oelze, M., Kalinovic, S., Stamm, P., et al. (2020). Environmental Aircraft Noise Aggravates Oxidative DNA Damage,
Granulocyte Oxidative Burst and Nitrate Resistance in Ogg1-/- Mice. Free Radic. Res. 54, 280-292. doi:10.1080/10715762.2020.1754410

Laursen, J. B., Rajagopalan, S., Galis, Z., Tarpey, M., Freeman, B. A., and Harrison, D. G. (1997). Role of Superoxide in Angiotensin II-Induced but Not Catecholamine-Induced Hypertension. Circulation 95, 588-593. doi:10.1161/ 01.cir.95.3.588

Lavinsky, J., Kasperbauer, G., Bento, R. F., Mendonça, A., Wang, J., Crow, A. L., et al. (2021). Noise Exposure and Distortion Product Otoacoustic Emission Suprathreshold Amplitudes: A Genome-wide Association Study. Audiol. Neurotol 1, 1-9. doi:10.1159/000514143

Leisegang, M. S., Schröder, K., and Brandes, R. P. (2018). Redox Regulation and Noncoding RNAs. Antioxid. Redox Signaling 29, 793-812. doi:10.1089/ ars.2017.7276

Lelieveld, J., Evans, J. S., Fnais, M., Giannadaki, D., and Pozzer, A. (2015). The Contribution of Outdoor Air Pollution Sources to Premature Mortality on a Global Scale. Nature 525, 367-371. doi:10.1038/nature15371

Lenzi, P., Frenzilli, G., Gesi, M., Ferrucci, M., Lazzeri, G., Fornai, F., et al. (2003). DNA Damage Associated with Ultrastructural Alterations in Rat Myocardium after Loud Noise Exposure. Environ. Health Perspect. 111, 467-471. doi:10.1289/ehp. 5847

Leso, V., Fontana, L., Finiello, F., De Cicco, L., Luigia Ercolano, M., and Iavicoli, I. (2020). Noise Induced Epigenetic Effects: A Systematic Review. Noise Health 22, 77-89. doi:10.4103/nah.NAH_17_20

Li, H., Kilgallen, A. B., Münzel, T., Wolf, E., Lecour, S., Schulz, R., et al. (2020a). Influence of Mental Stress and Environmental Toxins on Circadian Clocks: Implications for Redox Regulation of the Heart and Cardioprotection. Br. J. Pharmacol. 177, 5393-5412. doi:10.1111/bph.14949

Li, H., Kilgallen, A. B., Münzel, T., Wolf, E., Lecour, S., Schulz, R., et al. (2020). Influence of Mental Stress and Environmental Toxins on Circadian Clocks: Implications for Redox Regulation of the Heart and Cardioprotection. $\mathrm{Br}$. J. Pharmacol. 177, 5393-5412. doi:10.1111/bph.14949

Li, L., Chu, Y., Fink, G. D., Engelhardt, J. F., Heistad, D. D., and Chen, A. F. (2003a). Endothelin-1 Stimulates Arterial VCAM-1 Expression via NADPH OxidaseDerived Superoxide in Mineralocorticoid Hypertension. Hypertension 42, 997-1003. doi:10.1161/01.HYP.0000095980.43859.59

Li, L., Fink, G. D., Watts, S. W., Northcott, C. A., Galligan, J. J., Pagano, P. J., et al. (2003b). Endothelin-1 Increases Vascular Superoxide via Endothelin A -NADPH Oxidase Pathway in Low-Renin Hypertension. Circulation 107, 1053-1058. doi:10.1161/01.cir.0000051459.74466.46

Li, L., Watts, S. W., Banes, A. K., Galligan, J. J., Fink, G. D., and Chen, A. F. (2003c). NADPH Oxidase-Derived Superoxide Augments Endothelin-1-Induced Venoconstriction in Mineralocorticoid Hypertension. Hypertension 42, 316-321. doi:10.1161/01.HYP.0000084853.47326.F2

Li, X., Dong, Q., Wang, B., Song, H., Wang, S., and Zhu, B. (2019b). The Influence of Occupational Noise Exposure on Cardiovascular and Hearing Conditions Among Industrial Workers. Sci. Rep. 9, 11524. doi:10.1038/ s41598-019-47901-2

Lin, M. I., Fulton, D., Babbitt, R., Fleming, I., Busse, R., Pritchard, K. A., Jr., et al. (2003). Phosphorylation of Threonine 497 in Endothelial Nitric-Oxide Synthase Coordinates the Coupling of L-Arginine Metabolism to Efficient Nitric Oxide Production. J. Biol. Chem. 278, 44719-44726. doi:10.1074/ jbc.M302836200

Liu, L., Fang, C., Yang, J., Zhang, H., Huang, Y., Xuan, C., et al. (2018a). The Effect of Noise Exposure on Insulin Sensitivity in Mice May Be Mediated by the JNK/ IRS1 Pathway. Environ. Health Prev. Med. 23, 6. doi:10.1186/s12199-0180694-3

Liu, L., Huang, Y., Fang, C., Zhang, H., Yang, J., Xuan, C., et al. (2018b). Chronic Noise-Exposure Exacerbates Insulin Resistance and Promotes the Manifestations of the Type 2 Diabetes in a High-Fat Diet Mouse Model. PLoS One 13, e0195411. doi:10.1371/journal.pone.0195411

Liu, L., Wang, F., Lu, H., Cao, S., Du, Z., Wang, Y., et al. (2016). Effects of Noise Exposure on Systemic and Tissue-Level Markers of Glucose Homeostasis and Insulin Resistance in Male Mice. Environ. Health Perspect. 124, 1390-1398. doi:10.1289/EHP162

Loot, A. E., Schreiber, J. G., Fisslthaler, B., and Fleming, I. (2009). Angiotensin II Impairs Endothelial Function via Tyrosine Phosphorylation of the Endothelial Nitric Oxide Synthase. J. Exp. Med. 206, 2889-2896. doi:10.1084/jem.20090449 
Lousinha, A., Pereira, G., Borrecho, G., Brito, J., Oliveira De Carvalho, A., Freitas, D., et al. (2020). Atrial Fibrosis and Decreased Connexin 43 in Rat Hearts after Exposure to High-Intensity Infrasound. Exp. Mol. Pathol. 114, 104409. doi:10.1016/j.yexmp.2020.104409

Lousinha, A., R. Oliveira, M. J., Borrecho, G., Brito, J., Oliveira, P., Oliveira De Carvalho, A., et al. (2018). Infrasound Induces Coronary Perivascular Fibrosis in Rats. Cardiovasc. Pathol. 37, 39-44. doi:10.1016/j.carpath.2018.10.004

Lv, H., Zhu, C. a., Wu, R., Ni, H., Lian, J., Xu, Y., et al. (2019). Chronic Mild Stress Induced Anxiety-like Behaviors Can Be Attenuated by Inhibition of NOX2Derived Oxidative Stress. J. Psychiatr. Res. 114, 55-66. doi:10.1016/ j.jpsychires.2019.04.008

Lyamin, O. I., Korneva, S. M., Rozhnov, V. V., and Mukhametov, L. M. (2016). Cardiorespiratory Responses to Acoustic Noise in Belugas. Adv. Exp. Med. Biol. 875, 665-672. doi:10.1007/978-1-4939-2981-8_80

Medic, G., Wille, M., and Hemels, M. (2017). Short- and Long-Term Health Consequences of Sleep Disruption. Nss 9, 151-161. doi:10.2147/ NSS.S134864

Meehan, D. T., Delimont, D., Dufek, B., Zallocchi, M., Phillips, G., Gratton, M. A., et al. (2016). Endothelin-1 Mediated Induction of Extracellular Matrix Genes in Strial Marginal Cells Underlies Strial Pathology in Alport Mice. Hearing Res. 341, 100-108. doi:10.1016/j.heares.2016.08.003

Meerson, A., Cacheaux, L., Goosens, K. A., Sapolsky, R. M., Soreq, H., and Kaufer, D. (2010). Changes in Brain MicroRNAs Contribute to Cholinergic Stress Reactions. J. Mol. Neurosci. 40, 47-55. doi:10.1007/s12031-009-9252-1

Michaud, D., Konkle, A. M., Keith, S., and McNamee, J. (2017). Chronic Noise Exposure in the Spontaneously Hypertensive Rat. Noise Health 19, 213-221. doi:10.4103/nah.NAH_15_17

Miguel, V., Cui, J. Y., Daimiel, L., Espinosa-Díez, C., Fernández-Hernando, C., Kavanagh, T. J., et al. (2018). The Role of MicroRNAs in Environmental Risk Factors, Noise-Induced Hearing Loss, and Mental Stress. Antioxid. Redox Signaling 28, 773-796. doi:10.1089/ars.2017.7175

Miguel, V., Lamas, S., and Espinosa-Diez, C. (2020). Role of Non-coding-RNAs in Response to Environmental Stressors and Consequences on Human Health. Redox Biol. 37, 101580. doi:10.1016/j.redox.2020.101580

Mikhed, Y., Görlach, A., Knaus, U. G., and Daiber, A. (2015). Redox Regulation of Genome Stability by Effects on Gene Expression, Epigenetic Pathways and DNA Damage/repair. Redox Biol. 5, 275-289. doi:10.1016/j.redox.2015.05.008

Morakinyo, A. O., Samuel, T. A., Awobajo, F. O., Adekunbi, D. A., Olatunji, I. O., Binibor, F. U., et al. (2019). Adverse Effects of Noise Stress on Glucose Homeostasis and Insulin Resistance in Sprague-Dawley Rats. Heliyon 5, e03004. doi:10.1016/j.heliyon.2019.e03004

Morris, C. J., Purvis, T. E., Hu, K., and Scheer, F. A. J. L. (2016). Circadian Misalignment Increases Cardiovascular Disease Risk Factors in Humans. Proc. Natl. Acad. Sci. USA 113, E1402-E1411. doi:10.1073/pnas.1516953113

Morvai, V., Szakmáry, E., Székely, A., and Ungváry, G. (1994). The Combined Cardiovascular Effect of Alcohol and Noise in Rats. Acta Physiol. Hung 82, 301-311.

Mount, P. F., Kemp, B. E., and Power, D. A. (2007). Regulation of Endothelial and Myocardial NO Synthesis by Multi-Site eNOS Phosphorylation. J. Mol. Cell Cardiol. 42, 271-279. doi:10.1016/j.yjmcc.2006.05.023

Münzel, T., Daiber, A., Steven, S., Tran, L. P., Ullmann, E., Kossmann, S., et al. (2017). Effects of Noise on Vascular Function, Oxidative Stress, and Inflammation: Mechanistic Insight from Studies in Mice. Eur. Heart J. 38, 2838-2849. doi:10.1093/eurheartj/ehx081

Münzel, T., Kröller-Schön, S., Oelze, M., Gori, T., Schmidt, F. P., Steven, S., et al. (2020). Adverse Cardiovascular Effects of Traffic Noise with a Focus on Nighttime Noise and the New WHO Noise Guidelines. Annu. Rev. Public Health 41, 309-328. doi:10.1146/annurev-publhealth-081519-062400

Münzel, T., Schmidt, F. P., Steven, S., Herzog, J., Daiber, A., and Sørensen, M. (2018a). Environmental Noise and the Cardiovascular System. J. Am. Coll. Cardiol. 71, 688-697. doi:10.1016/j.jacc.2017.12.015

Münzel, T., Sørensen, M., and Daiber, A. (2021a). Transportation Noise Pollution and Cardiovascular Disease. Nat. Rev. Cardiol. 18, 619-636. doi:10.1038/ s41569-021-00532-5

Münzel, T., Sørensen, M., Lelieveld, J., Hahad, O., Al-Kindi, S., Nieuwenhuijsen, M., et al. (2021b). Heart Healthy Cities: Genetics Loads the Gun but the Environment Pulls the Trigger. Eur. Heart J. 42, 2422-2438. doi:10.1093/ eurheartj/ehab235
Münzel, T., Sørensen, M., Schmidt, F., Schmidt, E., Steven, S., Kröller-Schön, S., et al. (2018b). The Adverse Effects of Environmental Noise Exposure on Oxidative Stress and Cardiovascular Risk. Antioxid. Redox Signaling 28, 873-908. doi:10.1089/ars.2017.7118

Murdoch, C. E., Alom-Ruiz, S. P., Wang, M., Zhang, M., Walker, S., Yu, B., et al. (2011). Role of Endothelial Nox2 NADPH Oxidase in Angiotensin II-Induced Hypertension and Vasomotor Dysfunction. Basic Res. Cardiol. 106, 527-538. doi:10.1007/s00395-011-0179-7

Ordovás, J. M., and Smith, C. E. (2010). Epigenetics and Cardiovascular Disease. Nat. Rev. Cardiol. 7, 510-519. doi:10.1038/nrcardio.2010.104

Osborne, M. T., Naddaf, N., Abohashem, S., Radfar, A., Ghoneem, A., Dar, T., et al. (2021). A Neurobiological Link between Transportation Noise Exposure and Metabolic Disease in Humans. Psychoneuroendocrinology 131, 105331. doi:10.1016/j.psyneuen.2021.105331

Osborne, M. T., Radfar, A., Hassan, M. Z. O., Abohashem, S., Oberfeld, B., Patrich, T., et al. (2020). A Neurobiological Mechanism Linking Transportation Noise to Cardiovascular Disease in Humans. Eur. Heart J. 41, 772-782. doi:10.1093/ eurheartj/ehz820

Ouyang, J.-S., Li, Y.-P., Li, C.-Y., Cai, C., Chen, C.-S., Chen, S.-X., et al. (2012). Mitochondrial ROS-K+channel Signaling Pathway Regulated Secretion of Human Pulmonary Artery Endothelial Cells. Free Radic. Res. 46, 1437-1445. doi:10.3109/10715762.2012.724532

Paparelli, A., Soldani, P., Breschi, M. C., Martinotti, E., Scatizzi, R., Berrettini, S., et al. (1992). Effects of Subacute Exposure to Noise on the Noradrenergic Innervation of the Cardiovascular System in Young and Aged Rats: a Morphofunctional Study. J. Neural Transm. 88, 105-113. doi:10.1007/ BF01244816

Park, J.-s., Cederroth, C. R., Basinou, V., Meltser, I., Lundkvist, G., and Canlon, B. (2016). Identification of a Circadian Clock in the Inferior Colliculus and its Dysregulation by Noise Exposure. J. Neurosci. 36, 5509-5519. doi:10.1523/ JNEUROSCI.3616-15.2016

Peterson, E. A., Augenstein, J. S., Hazelton, C. L., Hetrick, D., Levene, R. M., and Tanis, D. C. (1984a). Some Cardiovascular Effects of Noise. J. Aud Res. 24, 35-62.

Peterson, E. A., Haselton, C. L., and Augenstein, J. S. (1984b). Daily Noise Duration Influences Cardiovascular Responses. J. Aud Res. 24, 69-86.

Peterson, E. A., Augenstein, J. S., Tanis, D. C., and Augenstein, D. G. (1981). Noise Raises Blood Pressure without Impairing Auditory Sensitivity. Science 211, 1450-1452. doi:10.1126/science.7466404

Pew Research Center (2020). How the Coronavirus Outbreak Has - and Hasn't Changed the Way Americans Work. Available at: https://www.pewresearch. org/social-trends/2020/12/09/how-the-coronavirus-outbreak-has-and-hasntchanged-the-way-americans-work/.

Putker, M., and O'neill, J. S. (2016). Reciprocal Control of the Circadian Clock and Cellular Redox State - a Critical Appraisal. Mol. Cells 39, 6-19. doi:10.14348/ molcells.2016.2323

Rajagopalan, S., Laursen, J. B., Borthayre, A., Kurz, S., Keiser, J., Haleen, S., et al. (1997). \E Role for Endothelin-1 in Angiotensin II- Mediated Hypertension. Hypertension 30, 29-34. doi:10.1161/01.hyp.30.1.29

Said, M. A., and El-Gohary, O. A. (2016). Effect of Noise Stress on Cardiovascular System in Adult Male Albino Rat: Implication of Stress Hormones, Endothelial Dysfunction and Oxidative Stress. gpb 35, 371-377. doi:10.4149/gpb_2016003

Sainani, K. (2016). Taking on the Exposome - Bringing Bioinformatics Tools to the Environmental Side of the Health Equation. BIOMEDICAL COMPUTATION REVIEW Fall, 14-21. Published by the Mobilize Center, an NIH Big Data to Knowledge Center of Excellence. https://mobilize.stanford.edu/wp-content/ uploads/2021/10/BCR-Fall-2016.pdf. (Accessed at: November 08, 2021).

Salvetti, F., Chelli, B., Gesi, M., Pellegrini, A., Giannaccini, G., Lucacchini, A., et al. (2000). Effect of Noise Exposure on Rat Cardiac Peripheral Benzodiazepine Receptors. Life Sci. 66, 1165-1175. doi:10.1016/s00243205(00)00422-7

Schmalen, I., Reischl, S., Wallach, T., Klemz, R., Grudziecki, A., Prabu, J. R., et al. (2014). Interaction of Circadian Clock Proteins CRY1 and PER2 Is Modulated by Zinc Binding and Disulfide Bond Formation. Cell 157, 1203-1215. doi:10.1016/j.cell.2014.03.057

Schmidt, F., Kolle, K., Kreuder, K., Schnorbus, B., Wild, P., Hechtner, M., et al. (2015). Nighttime Aircraft Noise Impairs Endothelial Function and Increases 
Blood Pressure in Patients with or at High Risk for Coronary Artery Disease. Clin. Res. Cardiol. 104, 23-30. doi:10.1007/s00392-014-0751-x

Schmidt, F. P., Basner, M., Kroger, G., Weck, S., Schnorbus, B., Muttray, A., et al. (2013). Effect of Nighttime Aircraft Noise Exposure on Endothelial Function and Stress Hormone Release in Healthy Adults. Eur. Heart J. 34, 3508-3514. doi:10.1093/eurheartj/eht269

Schmidt, F. P., Herzog, J., Schnorbus, B., Ostad, M. A., Lasetzki, L., Hahad, O., et al. (2021). The Impact of Aircraft Noise on Vascular and Cardiac Function in Relation to Noise Event Number: a Randomized Trial. Cardiovasc. Res. 117, 1382-1390. doi:10.1093/cvr/cvaa204

Schulz, E., Jansen, T., Wenzel, P., Daiber, A., and Münzel, T. (2008). Nitric Oxide, Tetrahydrobiopterin, Oxidative Stress, and Endothelial Dysfunction in Hypertension. Antioxid. Redox Signaling 10, 1115-1126. doi:10.1089/ ars.2007.1989

Schulz, E., Wenzel, P., Münzel, T., and Daiber, A. (2014). Mitochondrial Redox Signaling: Interaction of Mitochondrial Reactive Oxygen Species with Other Sources of Oxidative Stress. Antioxid. Redox Signaling 20, 308-324. doi:10.1089/ars.2012.4609

Setiadi, A., Korim, W. S., Elsaafien, K., and Yao, S. T. (2018). The Role of the BloodBrain Barrier in Hypertension. Exp. Physiol. 103, 337-342. doi:10.1113/ EP086434

Simpson, D. S. A., and Oliver, P. L. (2020). ROS Generation in Microglia: Understanding Oxidative Stress and Inflammation in Neurodegenerative Disease. Antioxidants 9, 743. doi:10.3390/antiox 9080743

Singewald, N., Kouvelas, D., Mostafa, A., Sinner, C., and Philippu, A. (2000). Release of Glutamate and GABA in the Amygdala of Conscious Rats by Acute Stress and Baroreceptor Activation: Differences between SHR and WKY Rats. Brain Res. 864, 138-141. doi:10.1016/s0006-8993(00)02172-7

Smiley, A., King, D., and Bidulescu, A. (2019). The Association between Sleep Duration and Metabolic Syndrome: The NHANES 2013/2014. Nutrients 11, 2582. doi:10.3390/nu11112582

Sørensen, M., Andersen, Z. J., Nordsborg, R. B., Becker, T., Tjønneland, A., Overvad, K., et al. (2013). Long-term Exposure to Road Traffic Noise and Incident Diabetes: a Cohort Study. Environ. Health Perspect. 121, 217-222. doi:10.1289/ehp.1205503

Sorensen, M., Hvidberg, M., Andersen, Z. J., Nordsborg, R. B., Lillelund, K. G., Jakobsen, J., et al. (2011). Road Traffic Noise and Stroke: a Prospective Cohort Study. Eur. Heart J. 32, 737-744. doi:10.1093/eurheartj/ehq466

Sorescu, D., Weiss, D., Lassègue, B., Clempus, R. E., Szöcs, K., Sorescu, G. P., et al. (2002). Superoxide Production and Expression of Nox Family Proteins in Human Atherosclerosis. Circulation 105, 1429-1435. doi:10.1161/ 01.cir.0000012917.74432.66

Spahis, S., Borys, J.-M., and Levy, E. (2017a). Metabolic Syndrome as a Multifaceted Risk Factor for Oxidative Stress. Antioxid. Redox Signaling 26, 445-461. doi:10.1089/ars.2016.6756

Spahis, S., Delvin, E., Borys, J.-M., and Levy, E. (2017b). Oxidative Stress as a Critical Factor in Nonalcoholic Fatty Liver Disease Pathogenesis. Antioxid. Redox Signaling 26, 519-541. doi:10.1089/ars.2016.6776

Stansfeld, S., Berglund, B., Clark, C., Lopez-Barrio, I., Fischer, P., Öhrström, E., et al. (2005). Aircraft and Road Traffic Noise and Children's Cognition and Health: a Cross-National Study. The Lancet 365, 1942-1949. doi:10.1016/ S0140-6736(05)66660-3

Steven, S., Frenis, K., Kalinovic, S., Kvandova, M., Oelze, M., Helmstädter, J., et al. (2020). Exacerbation of Adverse Cardiovascular Effects of Aircraft Noise in an Animal Model of Arterial Hypertension. Redox Biol. 34, 101515. doi:10.1016/ j.redox.2020.101515

Steven, S., Frenis, K., Oelze, M., Kalinovic, S., Kuntic, M., Bayo Jimenez, M. T., et al. (2019). Vascular Inflammation and Oxidative Stress: Major Triggers for Cardiovascular Disease. Oxidative Med. Cell Longevity 2019, 1-26. doi:10.1155/2019/7092151

Steven, S., Oelze, M., Brandt, M., Ullmann, E., Kröller-Schön, S., Heeren, T., et al. (2017). Pentaerythritol Tetranitrate In Vivo Treatment Improves Oxidative Stress and Vascular Dysfunction by Suppression of Endothelin-1 Signaling in Monocrotaline-Induced Pulmonary Hypertension. Oxidative Med. Cell Longevity 2017, 1-13. doi:10.1155/2017/4353462

Steven, S., Oelze, M., Hausding, M., Roohani, S., Kashani, F., Kröller-Schön, S., et al. (2018). The Endothelin Receptor Antagonist Macitentan Improves Isosorbide-5-Mononitrate (ISMN) and Isosorbide Dinitrate (ISDN) Induced
Endothelial Dysfunction, Oxidative Stress, and Vascular Inflammation. Oxidative Med. Cell Longevity 2018, 1-17. doi:10.1155/2018/7845629

Tak, S., Davis, R. R., and Calvert, G. M. (2009). Exposure to Hazardous Workplace Noise and Use of Hearing protection Devices Among US Workers-NHANES, 1999-2004. Am. J. Ind. Med. 52, 358-371. doi:10.1002/ajim.20690

The World Bank (2020). Urban Development. Available at: https://www. worldbank.org/en/topic/urbandevelopment/overview.

Thosar, S. S., Butler, M. P., and Shea, S. A. (2018). Role of the Circadian System in Cardiovascular Disease. J. Clin. Invest. 128, 2157-2167. doi:10.1172/ JCI80590

Tran, L. T., Macleod, K. M., and Mcneill, J. H. (2009). Endothelin-1 Modulates Angiotensin II in the Development of Hypertension in Fructose-Fed Rats. Mol. Cell Biochem 325, 89-97. doi:10.1007/s11010-008-0023-z

United Nations (2018). World Urbanization Prospects. Available at: https:// population.un.org/wup/Publications/Files/WUP2018-Report.pdf.

van Kempen, E., Casas, M., Pershagen, G., and Foraster, M. (2018). WHO Environmental Noise Guidelines for the European Region: A Systematic Review on Environmental Noise and Cardiovascular and Metabolic Effects: A Summary. Ijerph 15, 379. doi:10.3390/ijerph15020379

van Kempen, E. E. M. M., Kruize, H., Boshuizen, H. C., Ameling, C. B., Staatsen, B. A. M., and De Hollander, A. E. M. (2002). The ssociation between Noise Exposure and Blood Pressure and Ischemic Heart Disease: a Meta-Analysis. Environ. Health Perspect. 110, 307-317. doi:10.1289/ ehp.02110307

Van Laake, L. W., Lüscher, T. F., and Young, M. E. (2018). The Circadian Clock in Cardiovascular Regulation and Disease: Lessons from the Nobel Prize in Physiology or Medicine 2017. Eur. Heart J. 39, 2326-2329. doi:10.1093/ eurheartj/ehx775

Vineis, P., Robinson, O., Chadeau-Hyam, M., Dehghan, A., Mudway, I., and Dagnino, S. (2020). What Is New in the Exposome? Environ. Int. 143, 105887. doi:10.1016/j.envint.2020.105887

Vrijheid, M. (2014). The Exposome: a New Paradigm to Study the Impact of Environment on Health. Thorax 69, 876-878. doi:10.1136/thoraxjnl-2013204949

Wei, W., Shi, X., Xiong, W., He, L., Du, Z.-D., Qu, T., et al. (2020). RNA-seq Profiling and Co-expression Network Analysis of Long Noncoding RNAs and mRNAs Reveal Novel Pathogenesis of Noise-Induced Hidden Hearing Loss. Neuroscience 434, 120-135. doi:10.1016/ j.neuroscience.2020.03.023

Wenzel, P., Knorr, M., Kossmann, S., Stratmann, J., Hausding, M., Schuhmacher, S., et al. (2011). Lysozyme M-Positive Monocytes Mediate Angiotensin IIInduced Arterial Hypertension and Vascular Dysfunction. Circulation 124, 1370-1381. doi:10.1161/CIRCULATIONAHA.111.034470

Wenzel, P., Kossmann, S., Münzel, T., and Daiber, A. (2017). Redox Regulation of Cardiovascular Inflammation - Immunomodulatory Function of Mitochondrial and Nox-Derived Reactive Oxygen and Nitrogen Species. Free Radic. Biol. Med. 109, 48-60. doi:10.1016/ j.freeradbiomed.2017.01.027

Wild, C. P. (2005). Complementing the Genome with an "exposome": the Outstanding challenge of Environmental Exposure Measurement in Molecular Epidemiology. Cancer Epidemiol. Biomarkers Prev. 14, 1847-1850. doi:10.1158/1055-9965.EPI-05-0456

Yang, L., and Guthrie, O. n. W. (2020). Effects of Acute Noise Exposure on DNA Damage Response Genes in the Cochlea, Cortex, Heart and Liver. Exp. Mol. Pathol. 114, 104401. doi:10.1016/j.yexmp.2020.104401

Yu, Y., Paul, K., Arah, O. A., Mayeda, E. R., Wu, J., Lee, E., et al. (2020). Air Pollution, Noise Exposure, and Metabolic Syndrome - A Cohort Study in Elderly Mexican-Americans in Sacramento Area. Environ. Int. 134, 105269. doi:10.1016/j.envint.2019.105269

Zalba, G., Jose', G. S., Moreno, M. U., Fortuño, M. A., Fortuño, A., Beaumont, F. J., et al. (2001). Oxidative Stress in Arterial Hypertension. Hypertension 38, 1395-1399. doi:10.1161/hy1201.099611

Zou, M.-H., Shi, C., and Cohen, R. A. (2002). Oxidation of the ZincThiolate Complex and Uncoupling of Endothelial Nitric Oxide Synthase by Peroxynitrite. J. Clin. Invest. 109, 817-826. doi:10.1172/ jci0214442

Zymantiene, J., Zelvyte, R., Pampariene, I., Aniuliene, A., Juodziukyniene, N., Kantautaite, J., et al. (2017). Effects of Long-Term Construction Noise on 
Health of Adult Female Wistar Rats. Pol. J. Vet. Sci. 20, 155-165. doi:10.1515/ pjvs-2017-0020

Conflict of Interest: The authors declare that the research was conducted in the absence of any commercial or financial relationships that could be construed as a potential conflict of interest.

Publisher's Note: All claims expressed in this article are solely those of the authors and do not necessarily represent those of their affiliated organizations, or those of the publisher, the editors and the reviewers. Any product that may be evaluated in this article, or claim that may be made by its manufacturer, is not guaranteed or endorsed by the publisher.

Copyright (๑) 2021 Frenis, Kuntic, Hahad, Bayo Jimenez, Oelze, Daub, Steven, Münzel and Daiber. This is an open-access article distributed under the terms of the Creative Commons Attribution License (CC BY). The use, distribution or reproduction in other forums is permitted, provided the original author $(s)$ and the copyright owner(s) are credited and that the original publication in this journal is cited, in accordance with accepted academic practice. No use, distribution or reproduction is permitted which does not comply with these terms. 